\title{
Synthesis and thermal properties of bio-based copolyesters from the mixtures of 2,5- and 2,4-furandicarboxylic acid with different diols
}

Shanmugam Thiyagarajan, *a Michael A. Meijlink, a Aurélie Bourdet, ${ }^{a, b}$ Willem Vogelzang, ${ }^{a}$ Rutger J.I. Knoop, ${ }^{a}$ Antonella Esposito, ${ }^{* b}$ Eric Dargent, ${ }^{b}$ Daan S. van Es ${ }^{a}$ and Jacco van Haveren ${ }^{a}$

a. Wageningen Food and Biobased Research, Bornse Weilanden 9, 6708 WG, Wageningen, The Netherlands; shanmugam.thiyagarajan@wur.nl

b. Normandie Univ, UNIROUEN Normandie, INSA Rouen, CNRS, Groupe de Physique des Matériaux, 76000 Rouen; antonella.esposito@univ-rouen.fr

Electronic Supplementary Information

Contents:

*Note: all the NMR spectra were recorded using $\mathrm{CDCl}_{3}+\mathrm{TFA}-\mathrm{d}(6: 1)$ mixture.

Figure S1: ${ }^{1} \mathrm{H}$ NMR spectrum of Poly(1,2-ethylene-2,5-furandicarboxylate) (2,5-PEF)

Figure S2: ${ }^{13} \mathrm{C}$ NMR spectrum of Poly(1,2-ethylene-2,5-furandicarboxylate) (PEF)

Figure S3: ${ }^{1} \mathrm{H}$ NMR spectrum of Poly(1,2-ethylene-2,5[[95]-2,4[05]-furandicarboxylate) $(\mathrm{PE}-2,5[95]-2,4[05]-\mathrm{F})$

Figure S4: ${ }^{13} \mathrm{C}$ NMR spectrum of Poly(1,2-ethylene-2,5[95]-2,4[05]-furandicarboxylate) (PE-2,5[95]-2,4[05]-F)

Figure S5: ${ }^{1 H}$ NMR spectrum of Poly(1,2-ethylene-2,5[[90]-2,4[10]-furandicarboxylate) (PE-2,5[90]-2,4[10]-F)

Figure S6: ${ }^{13} \mathrm{C}$ NMR spectrum of Poly(1,2-ethylene-2,5[[90]-2,4[10]-furandicarboxylate) (PE-2,5[90]-2,4[10]-F)

Figure S7: ${ }^{1} \mathrm{H}$ NMR spectrum of Poly(1,2-ethylene-2,5[[85]-2,4[15]-furandicarboxylate) (PE-2,5[85]-2,4[15]-F)

Figure S8: ${ }^{13} \mathrm{C}$ NMR spectrum of Poly(1,2-ethylene-2,5[[85]-2,4[15]-furandicarboxylate) $(\mathrm{PE}-2,5[85]-2,4[15]-\mathrm{F})$

Figure 59: ${ }^{1 H}$ NMR spectrum of Poly(1,2-ethylene-2,5[[75]-2,4[25]-furandicarboxylate) (PE-2,5[75]-2,4[25]-F)

Figure S10: ${ }^{13} \mathrm{C}$ NMR spectrum of Poly(1,2-ethylene-2,5[[75]-2,4[25]-furandicarboxylate) $(\mathrm{PE}-2,5[75]-2,4[25]-\mathrm{F})$

Figure S11: ${ }^{1} \mathrm{H}$ NMR spectrum of Poly(1,2-ethylene-2,5[[50]-2,4[50]-furandicarboxylate) (PE-2,5[50]-2,4[50]-F)

Figure S12: ${ }^{13} \mathrm{C}$ NMR spectrum of Poly(1,2-ethylene-2,5[[50]-2,4[50]-furandicarboxylate) $(\mathrm{PE}-2,5[50]-2,4[50]-\mathrm{F})$

Figure S13: ${ }^{1} \mathrm{H}$ NMR spectrum of Poly(1,2-ethylene-2,5[[25]-2,4[75]-furandicarboxylate) (PE-2,5[25]-2,4[75]-F)

Figure S14: ${ }^{13} \mathrm{C}$ NMR spectrum of Poly(1,2-ethylene-2,5[[25]-2,4[75]-furandicarboxylate) (PE-2,5[25]-2,4[75]-F) 
Figure S15: ${ }^{1 H}$ NMR spectrum of Poly(1,2-ethylene-2,4-furandicarboxylate) (2,4-PEF)

Figure S16: ${ }^{13} \mathrm{C}$ NMR spectrum of Poly(1,2-ethylene-2,4-furandicarboxylate) (2,4-PEF)

Figure S17: ${ }^{1} \mathrm{H}$ NMR spectrum of PEF-2,5/2,4[H.M-A] (Henkel mixture A)

Figure S18: ${ }^{13} \mathrm{C}$ NMR spectrum of PEF-2,5/2,4[H.M-A] (Henkel mixture $A$ )

Figure S19: ${ }^{1} \mathrm{H}$ NMR spectrum of PEF-2,5/2,4[H.M-B] (Henkel mixture B)

Figure S20: ${ }^{13} \mathrm{C}$ NMR spectrum of PEF-2,5/2,4[H.M-B] (Henkel mixture B)

Figure S21: ${ }^{1} \mathrm{H}$ NMR spectrum of Poly(1,3-propylene-2,5-furandicarboxylate) (2,5-PPF)

Figure S22: ${ }^{13} \mathrm{C}$ NMR spectrum of Poly(1,3-propylene-2,5-furandicarboxylate) $(2,5-\mathrm{PPF})$

Figure S23: ${ }^{1} \mathrm{H}$ NMR spectrum of Poly(1,3-propylene-2,5[50]-2,4[50]-furandicarboxylate) (PP-2,5[50]-2,4[50]-F)

Figure S24: ${ }^{13} \mathrm{C}$ NMR spectrum of Poly(1,3-propylene-2,5[50]-2,4[50]-furandicarboxylate) (PP-2,5[50]-2,4[50]-F)

Figure S25: ${ }^{1} \mathrm{H}$ NMR spectrum of Poly(1,3-propylene-2,4-furandicarboxylate) (2,4-PPF)

Figure S26: ${ }^{13} \mathrm{C}$ NMR spectrum of Poly(1,3-propylene-2,4-furandicarboxylate) (2,4-PPF)

Figure S27: ${ }^{1} \mathrm{H}$ NMR spectrum of PPF-2,5/2,4[H.M-A] (Henkel mixture A)

Figure S28: ${ }^{13} \mathrm{C}$ NMR spectrum of PPF-2,5/2,4[H.M-A] (Henkel mixture $A$ )

Figure S29: ${ }^{1} \mathrm{H}$ NMR spectrum of PPF-2,5/2,4[H.M-B] (Henkel mixture B)

Figure S30: ${ }^{13} \mathrm{C}$ NMR spectrum of PPF-2,5/2,4[H.M-B] (Henkel mixture B)

Figure S31: ${ }^{1} \mathrm{H}$ NMR spectrum of Poly(1,4-butylene-2,5-furandicarboxylate) (2,5-PBF)

Figure S32: ${ }^{13} \mathrm{C}$ NMR spectrum of Poly(1,4-butylene-2,5-furandicarboxylate) $(2,5-\mathrm{PBF})$

Figure S33: ${ }^{1} \mathrm{H}$ NMR spectrum of Poly(1,4-butylene-2,5[50]-2,4[50]-furandicarboxylate) (PB-2,5[50]-2,4[50]-F)

Figure S34: ${ }^{13} \mathrm{C}$ NMR spectrum of Poly(1,4-butylene-2,5[50]-2,4[50]-furandicarboxylate) (PB-2,5[50]-2,4[50]-F)

Figure S35: ${ }^{1} \mathrm{H}$ NMR spectrum of Poly(1,4-butylene-2,4-furandicarboxylate) (2,4-PBF)

Figure S36: ${ }^{13} \mathrm{C}$ NMR spectrum of Poly(1,4-butylene-2,4-furandicarboxylate) (2,4-PBF)

Figure S37: ${ }^{1} \mathrm{H}$ NMR spectrum of PBF-2,5/2,4[H.M-A] (Henkel mixture A)

Figure S38: ${ }^{13} \mathrm{C}$ NMR spectrum of PBF-2,5/2,4[H.M-A] (Henkel mixture A)

Figure S39: ${ }^{1} \mathrm{H}$ NMR spectrum of PBF-2,5/2,4[H.M-B] (Henkel mixture $B$ )

Figure S40: ${ }^{13} \mathrm{C}$ NMR spectrum of PBF-2,5/2,4[H.M-B] (Henkel mixture B)

Figure S41: Activation energy for thermal degradation under gaseous nitrogen as a function of the degree of conversion (mass loss) for the polyesters in the EG series obtained by MT-TGA. 
Figure S42: Activation energy for thermal degradation under gaseous nitrogen as a function of the degree of conversion (mass loss) for the polyesters in the PDO series obtained by MT-TGA.

Figure 543: Activation energy for thermal degradation under gaseous nitrogen as a function of the degree of conversion (mass loss) for the polyesters in the BDO series obtained by MT-TGA.

Figure S44: TGA traces for the samples in (a) the EG, (b) the PDO, and (c) the BDO series recorded from 30 to $500^{\circ} \mathrm{C}$ at $10^{\circ} \mathrm{C} \mathrm{min}^{-1}$ under a $\mathrm{N}_{2}$ atmosphere.

Figure S45: WAXD diffractograms of (a) 2,5-PEF, (b) PE-2,5[95]-2,4[05]-F, (c) PE-2,5[90]-2,4[10]-F, (d) PE-2,5[85]-2,4[15]-F, (e) PE-2,5[75]-2,4[25]-F, (f) PE-2,5[50]-2,4[50]-F, (g) PE-2,5[25]-2,4[75]-F, (h) 2,4-PEF, (i) PEF-2,5/2,4[H.M-A] and (j) PEF-2,5/2,4[H.M-B].

Table S1: Percentage of DEG content in the EG series.

Modulated-Temperature Thermogravimetric Analysis (MT-TGA)

Metrics assessment for the Henkel reaction 
<smiles>CC(C)(C)CCOC(=O)c1ccc(C(=O)OC(C)(C)C)o1</smiles>

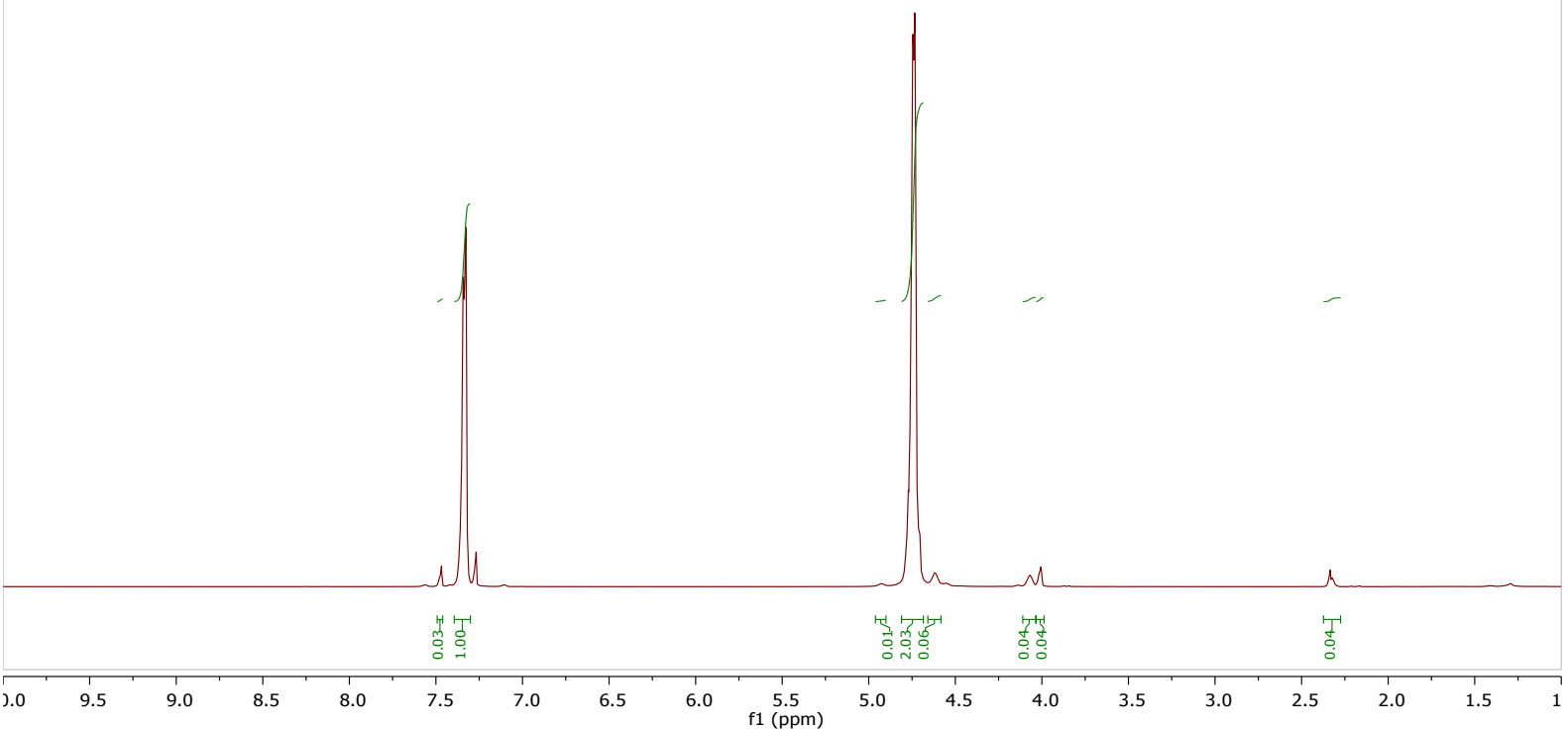

Figure S1: ${ }^{1} \mathrm{H}$ NMR spectrum of Poly(1,2-ethylene-2,5-furandicarboxylate) (2,5-PEF)

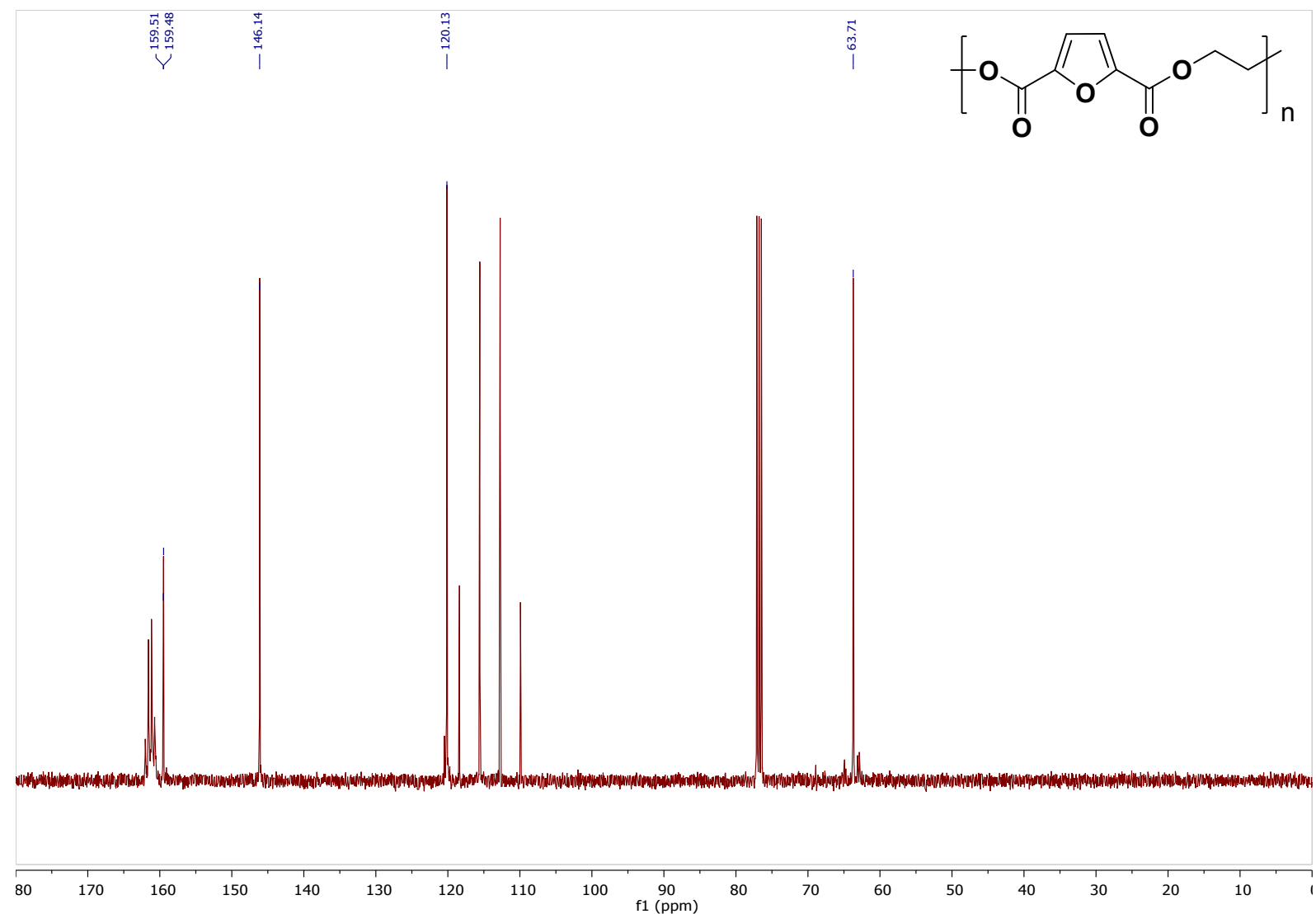

Figure S2: ${ }^{13} \mathrm{C}$ NMR spectrum of Poly(1,2-ethylene-2,5-furandicarboxylate) (PEF) 


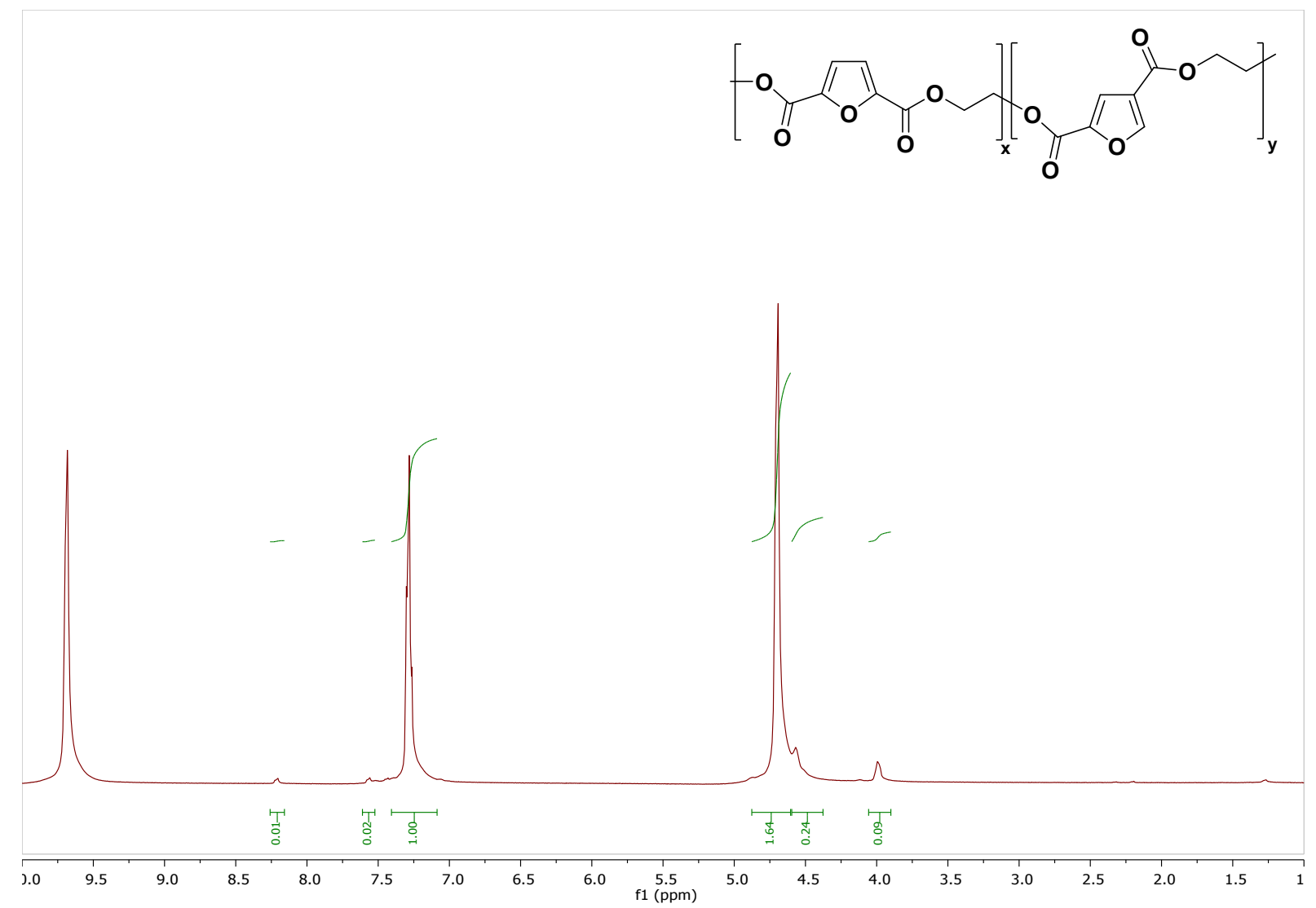

Figure S3: ${ }^{1} \mathrm{H}$ NMR spectrum of Poly(1,2-ethylene-2,5[[95]-2,4[05]-furandicarboxylate) (PE-2,5[95]$2,4[05]-F)$

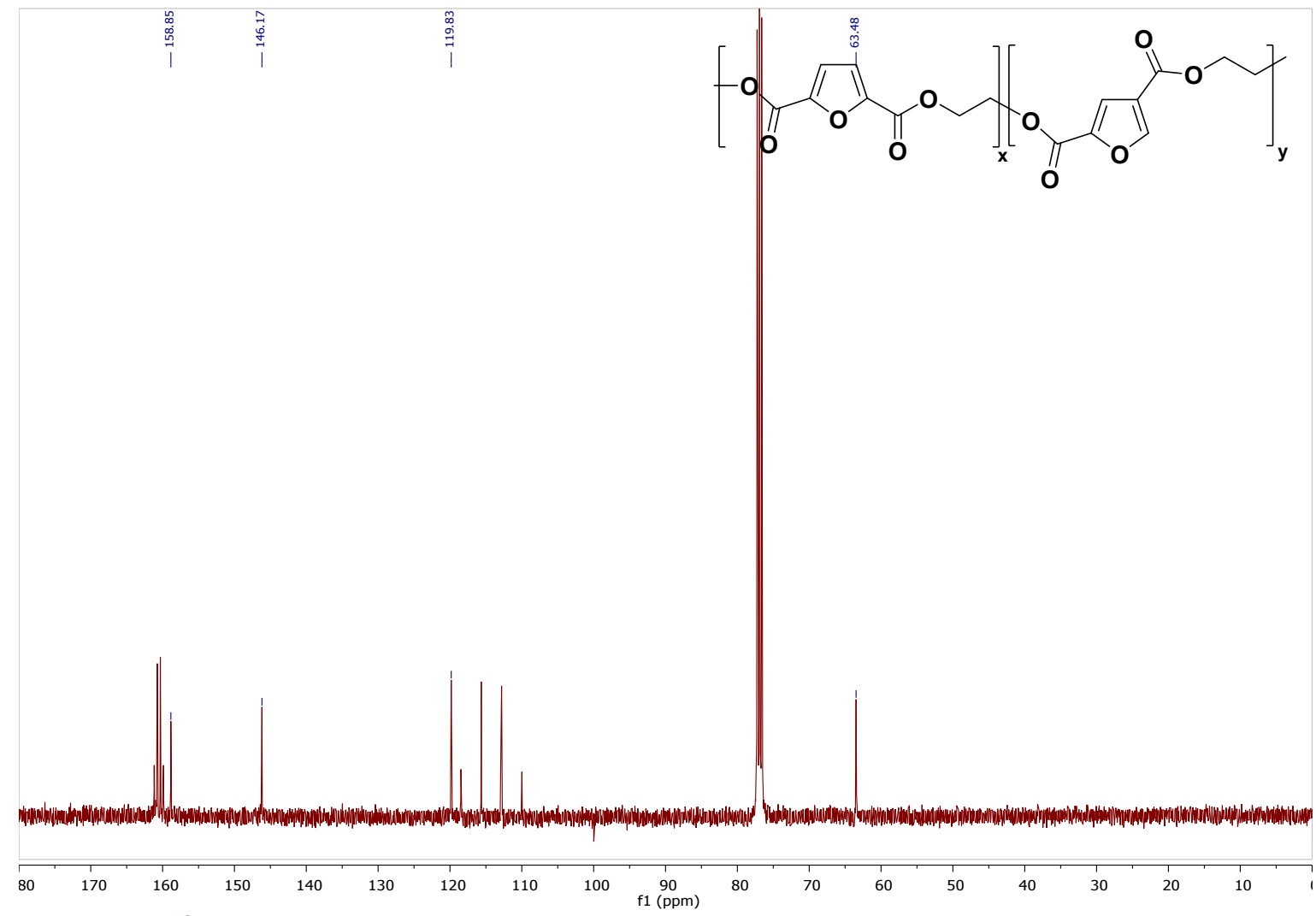

Figure S4: ${ }^{13} \mathrm{C}$ NMR spectrum of Poly(1,2-ethylene-2,5[95]-2,4[05]-furandicarboxylate) (PE-2,5[95]$2,4[05]-F)$ 


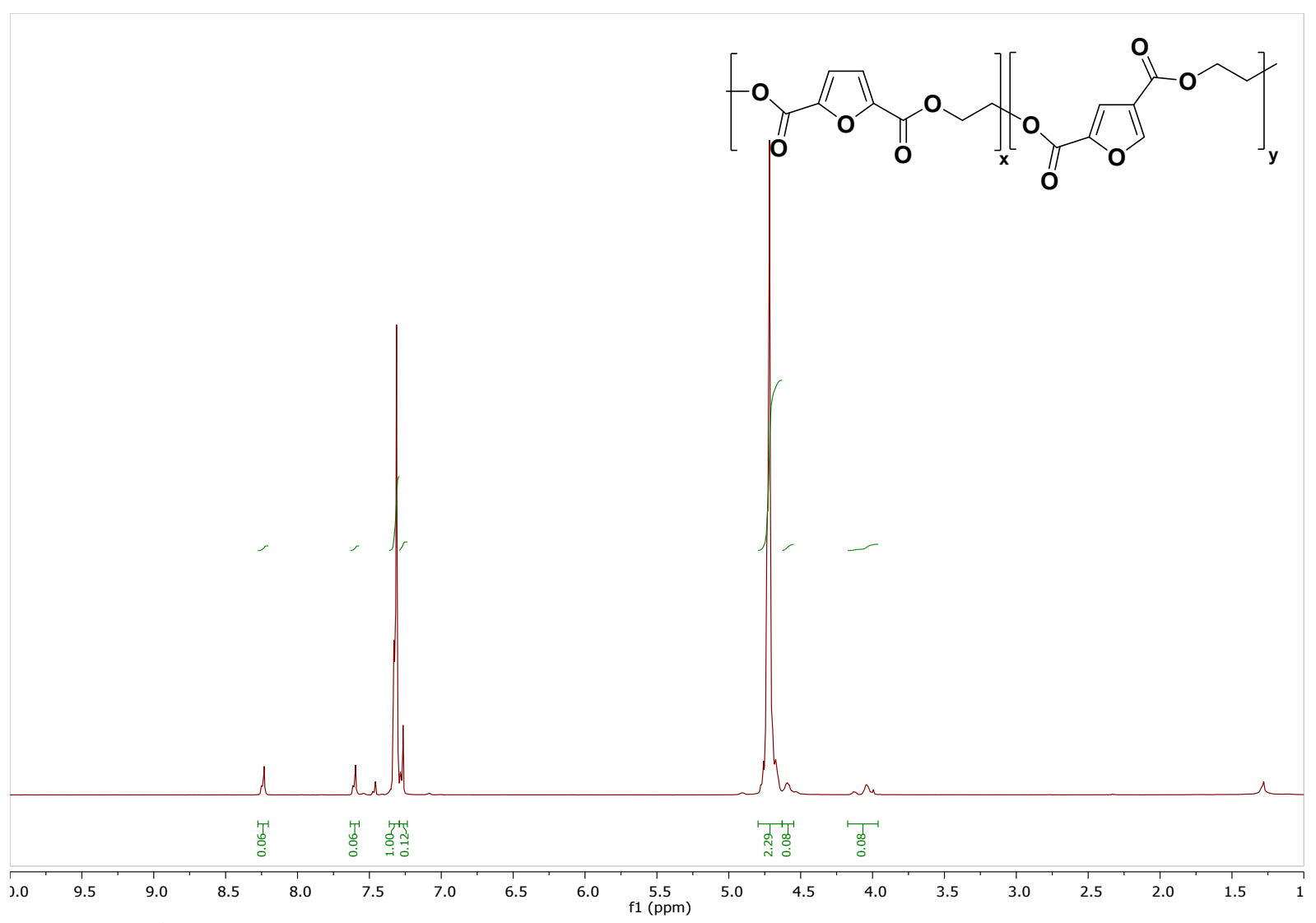

Figure S5: ${ }^{1} \mathrm{H}$ NMR spectrum of Poly(1,2-ethylene-2,5[[90]-2,4[10]-furandicarboxylate) (PE-2,5[90]$2,4[10]-F)$

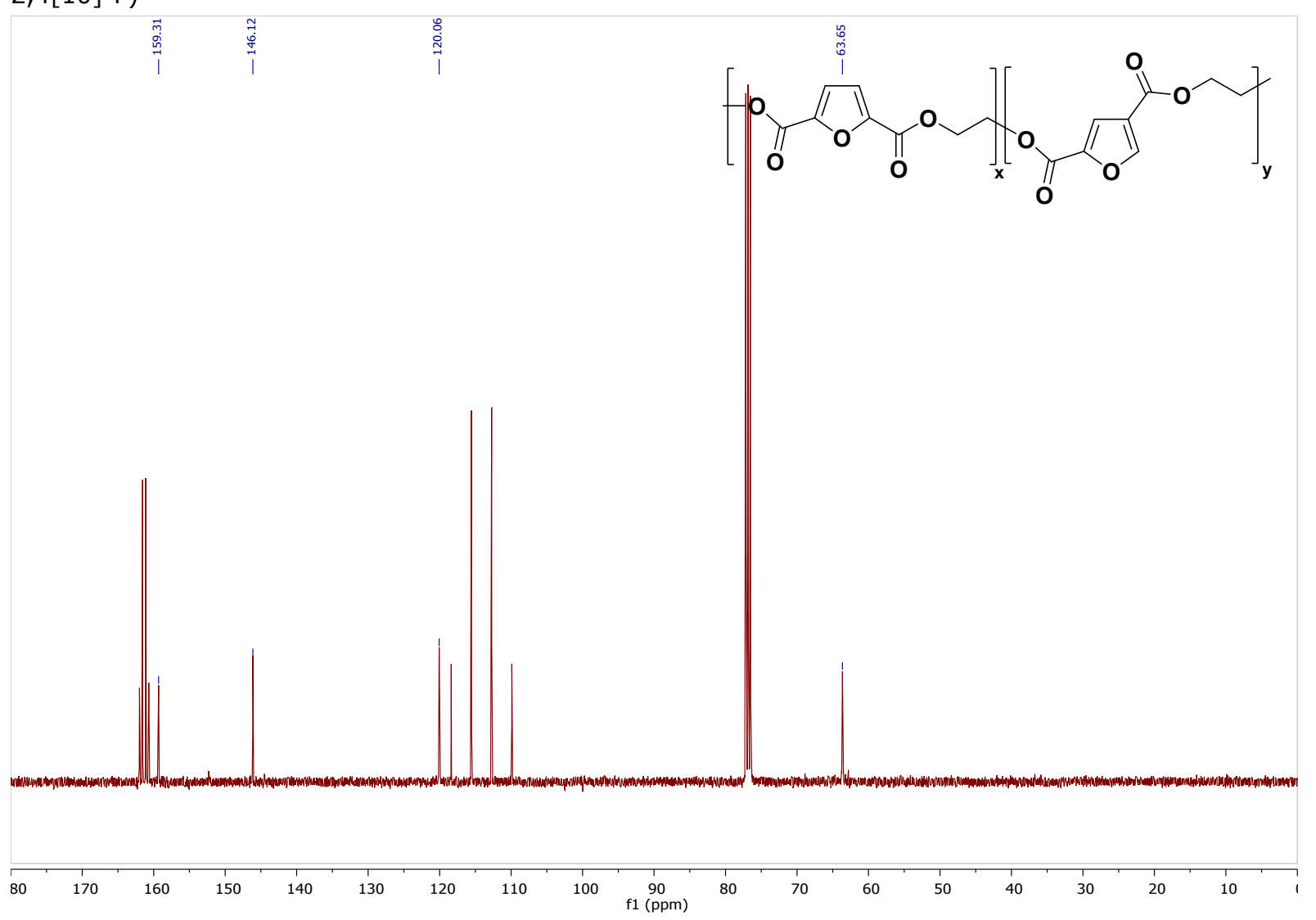

Figure S6: ${ }^{13} \mathrm{C}$ NMR spectrum of Poly(1,2-ethylene-2,5[[90]-2,4[10]-furandicarboxylate) (PE-2,5[90]$2,4[10]-F)$

S6 


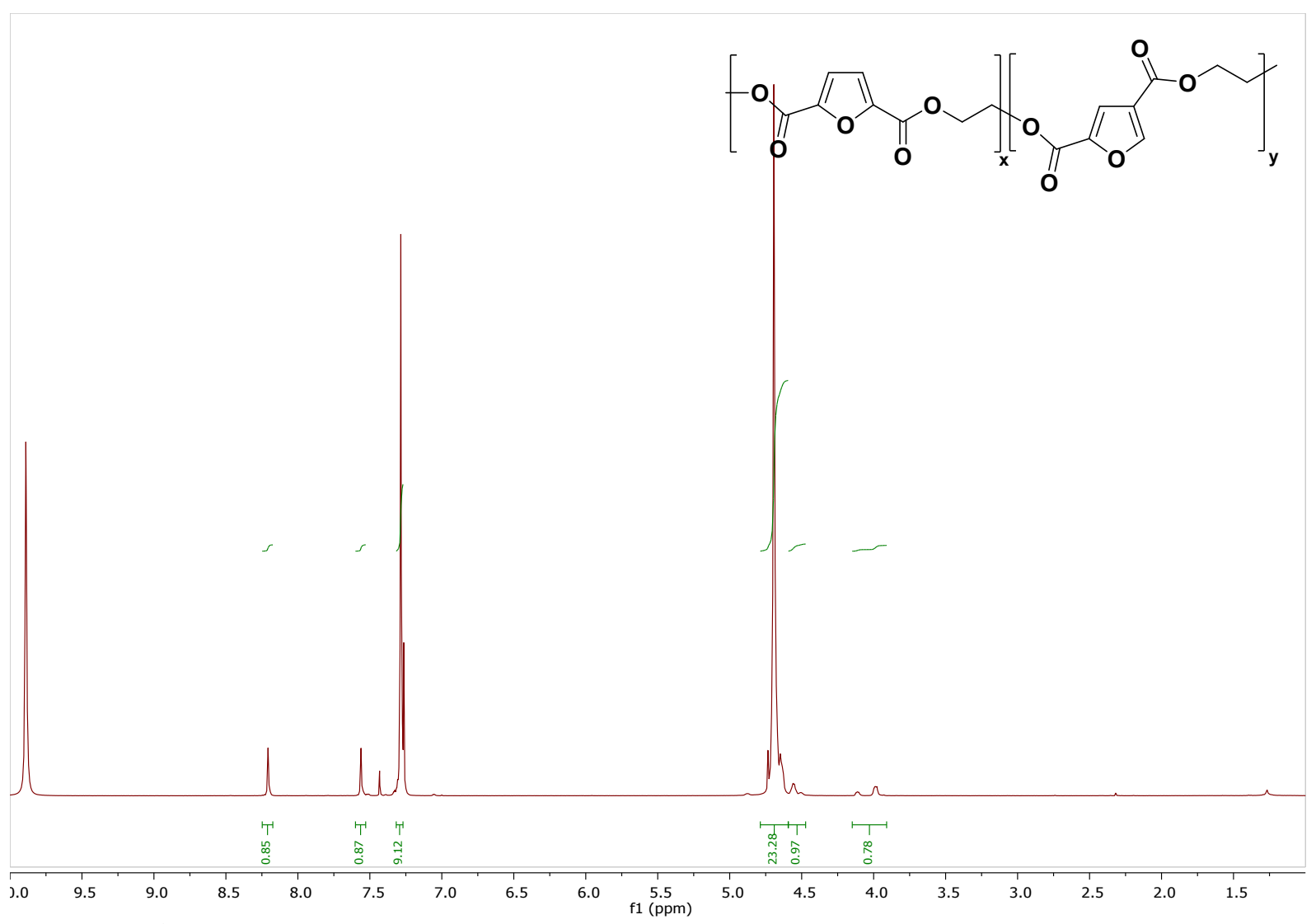

Figure S7: ${ }^{1} \mathrm{H}$ NMR spectrum of Poly(1,2-ethylene-2,5[[85]-2,4[15]-furandicarboxylate) (PE-2,5[85]$2,4[15]-F)$

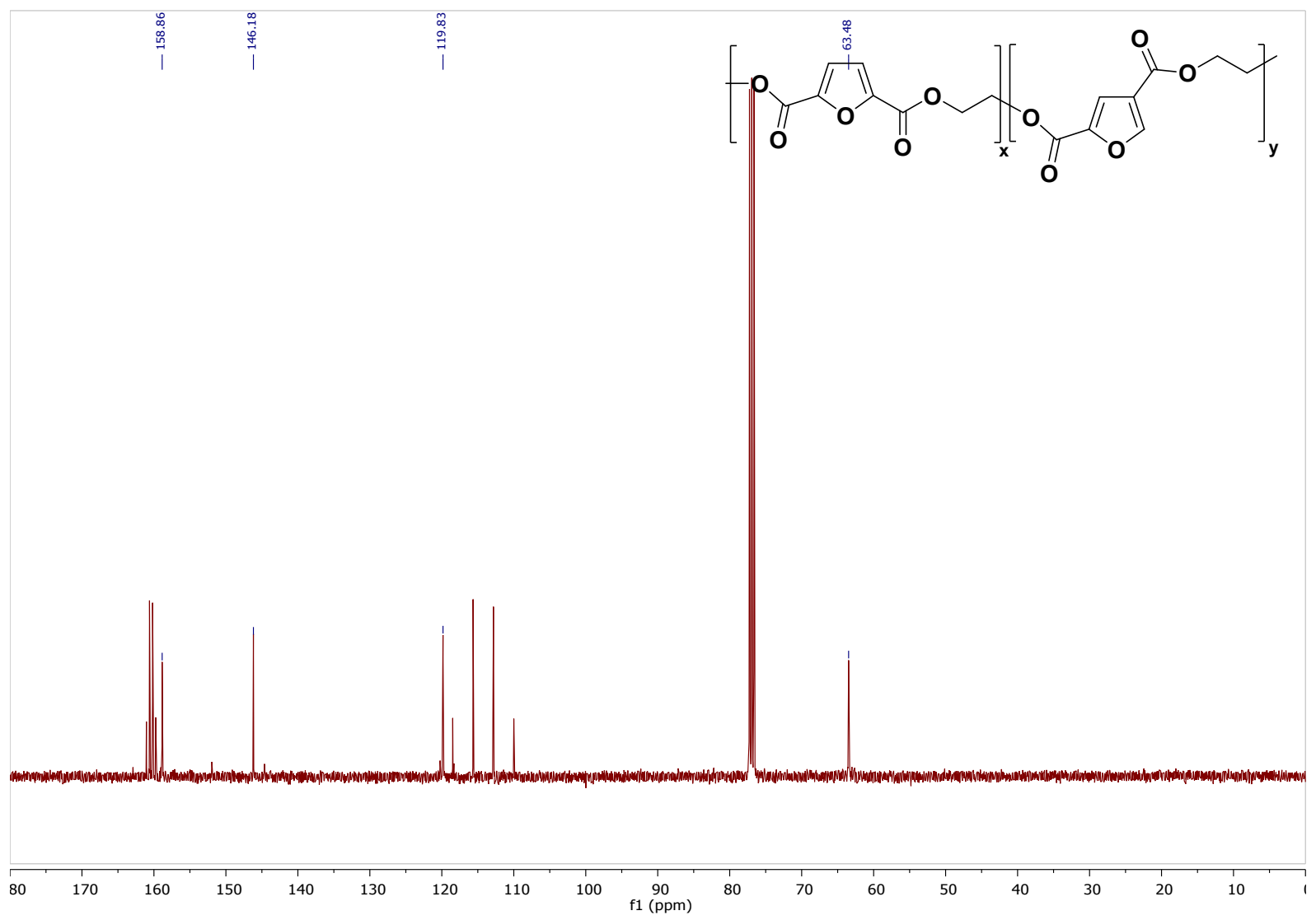

Figure S8: ${ }^{13} \mathrm{C}$ NMR spectrum of Poly(1,2-ethylene-2,5[[85]-2,4[15]-furandicarboxylate) (PE-2,5[85]$2,4[15]-F)$

S7 


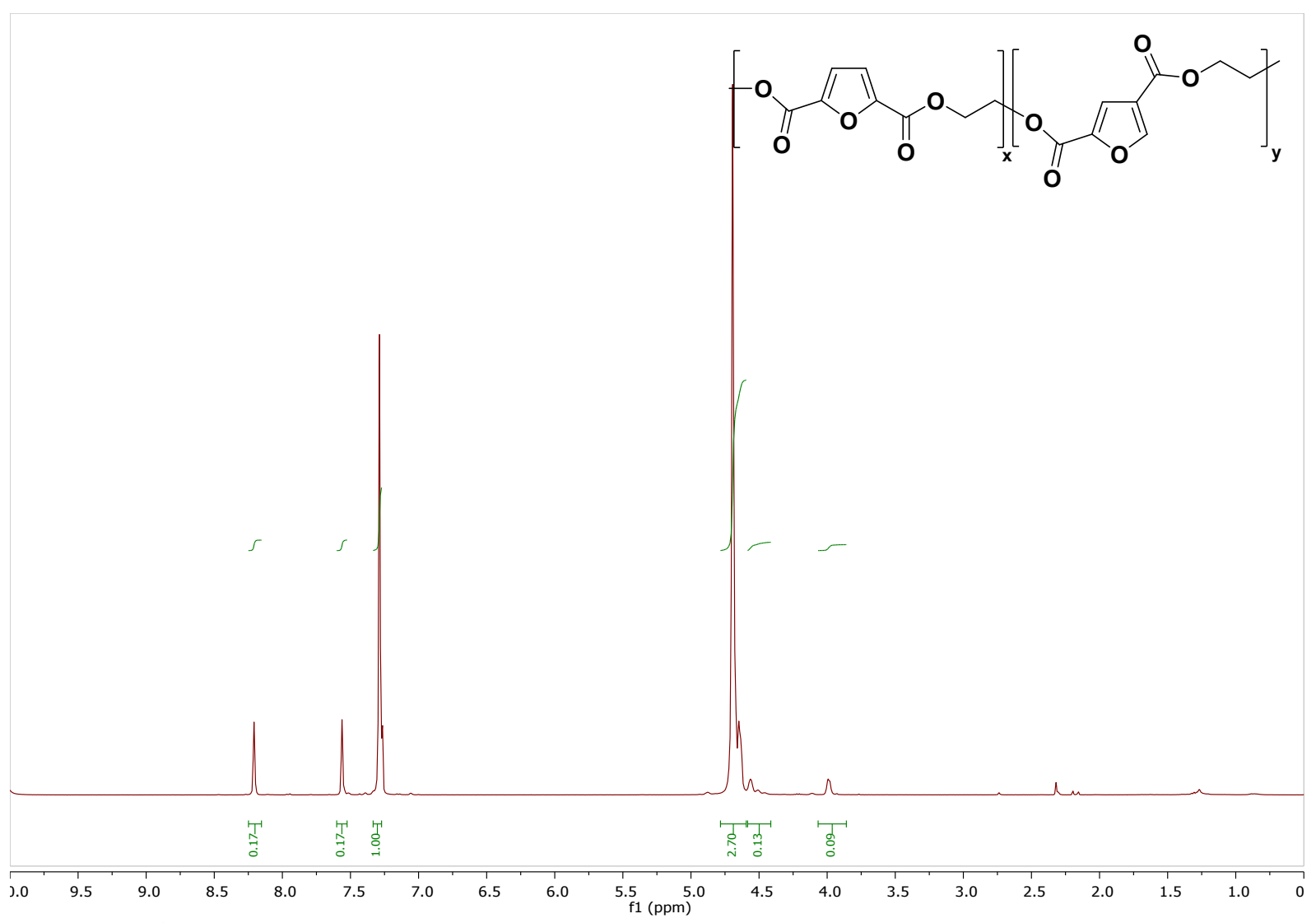

Figure S9: ${ }^{1} \mathrm{H}$ NMR spectrum of Poly(1,2-ethylene-2,5[[75]-2,4[25]-furandicarboxylate) (PE-2,5[75]$2,4[25]-F)$

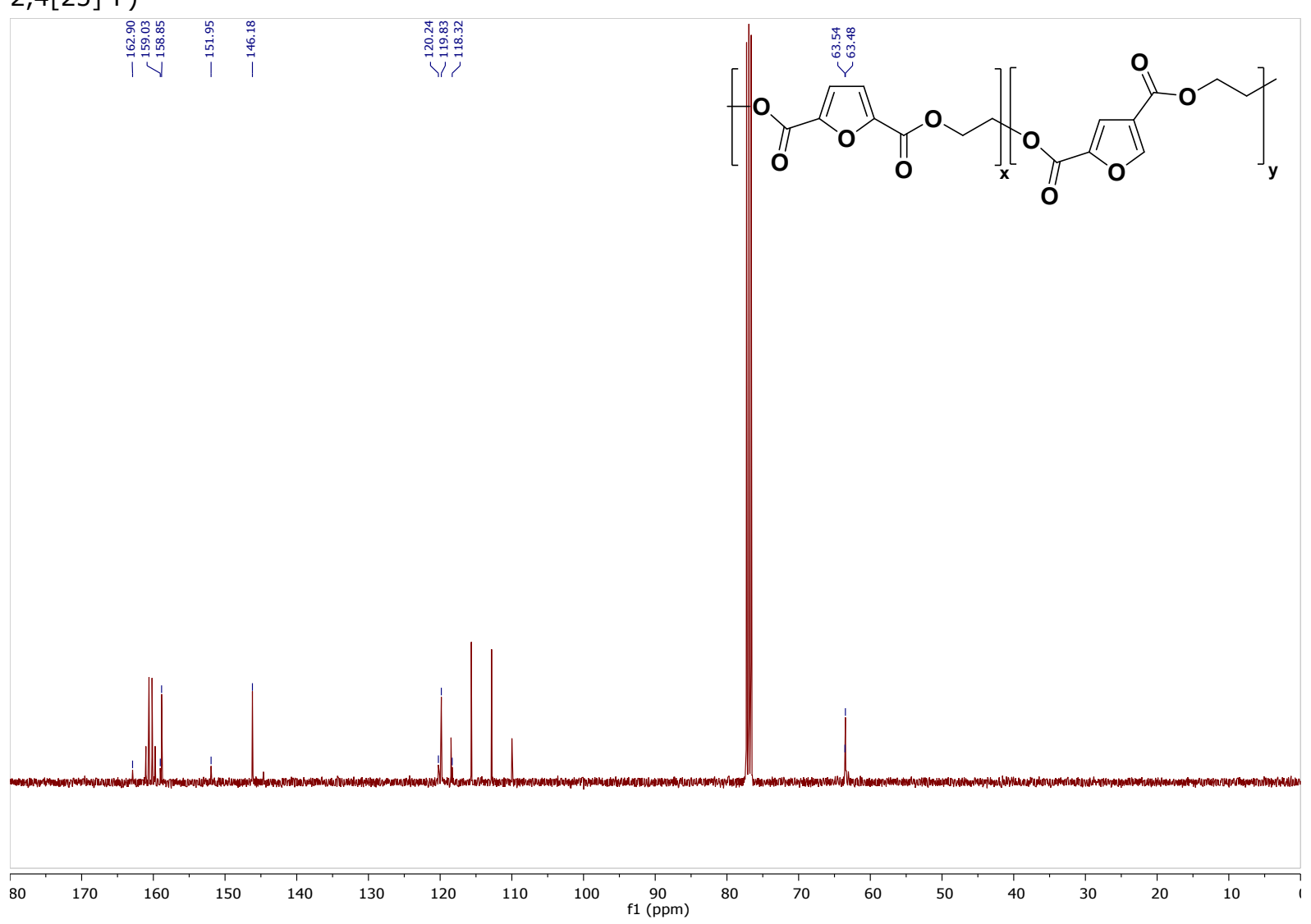

Figure S10: ${ }^{13} \mathrm{C}$ NMR spectrum of Poly(1,2-ethylene-2,5[[75]-2,4[25]-furandicarboxylate) (PE-2,5[75]$2,4[25]-F)$

S8 


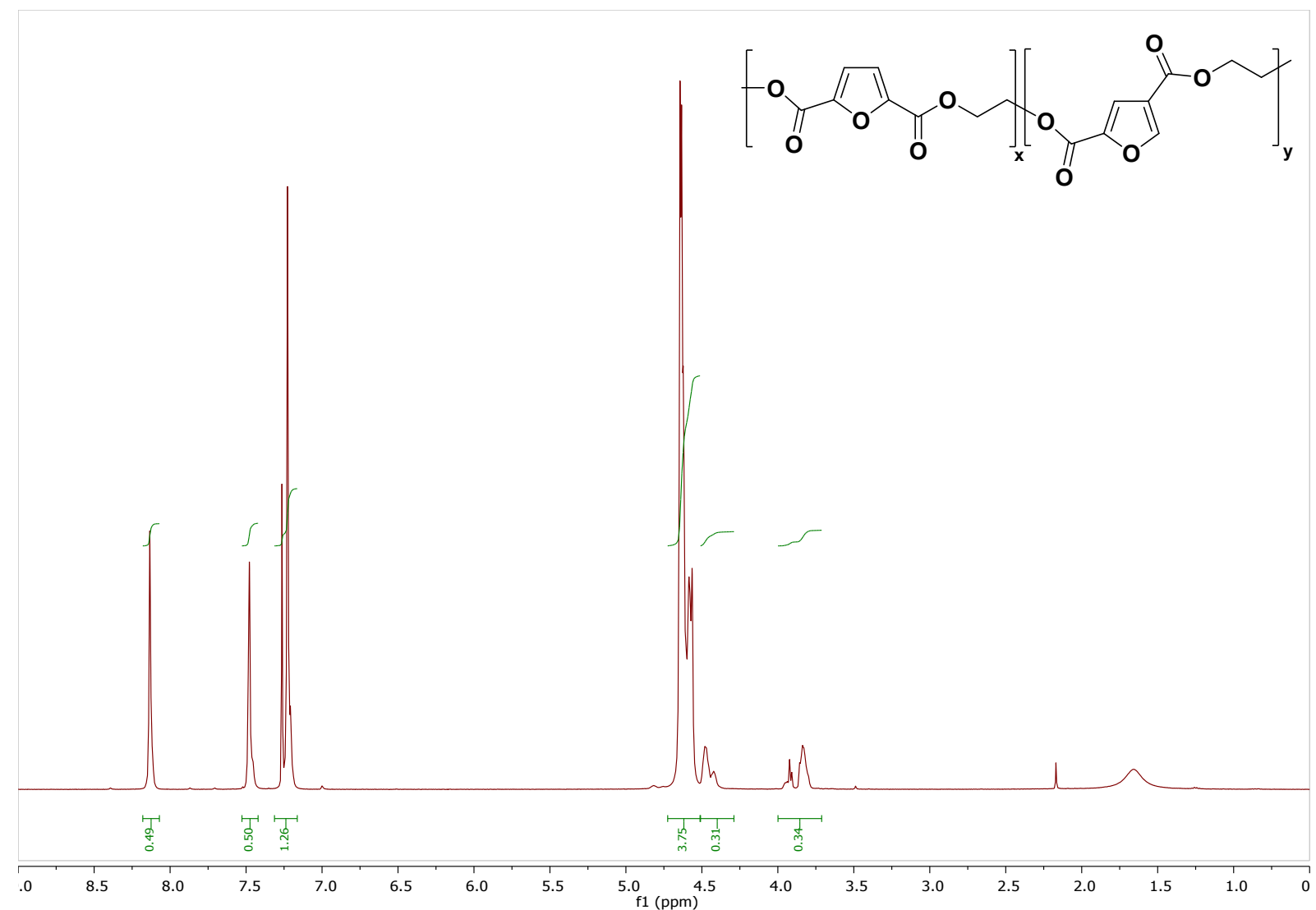

Figure S11: ${ }^{1} \mathrm{H}$ NMR spectrum of Poly(1,2-ethylene-2,5[[50]-2,4[50]-furandicarboxylate) (PE-2,5[50]$2,4[50]-F)$

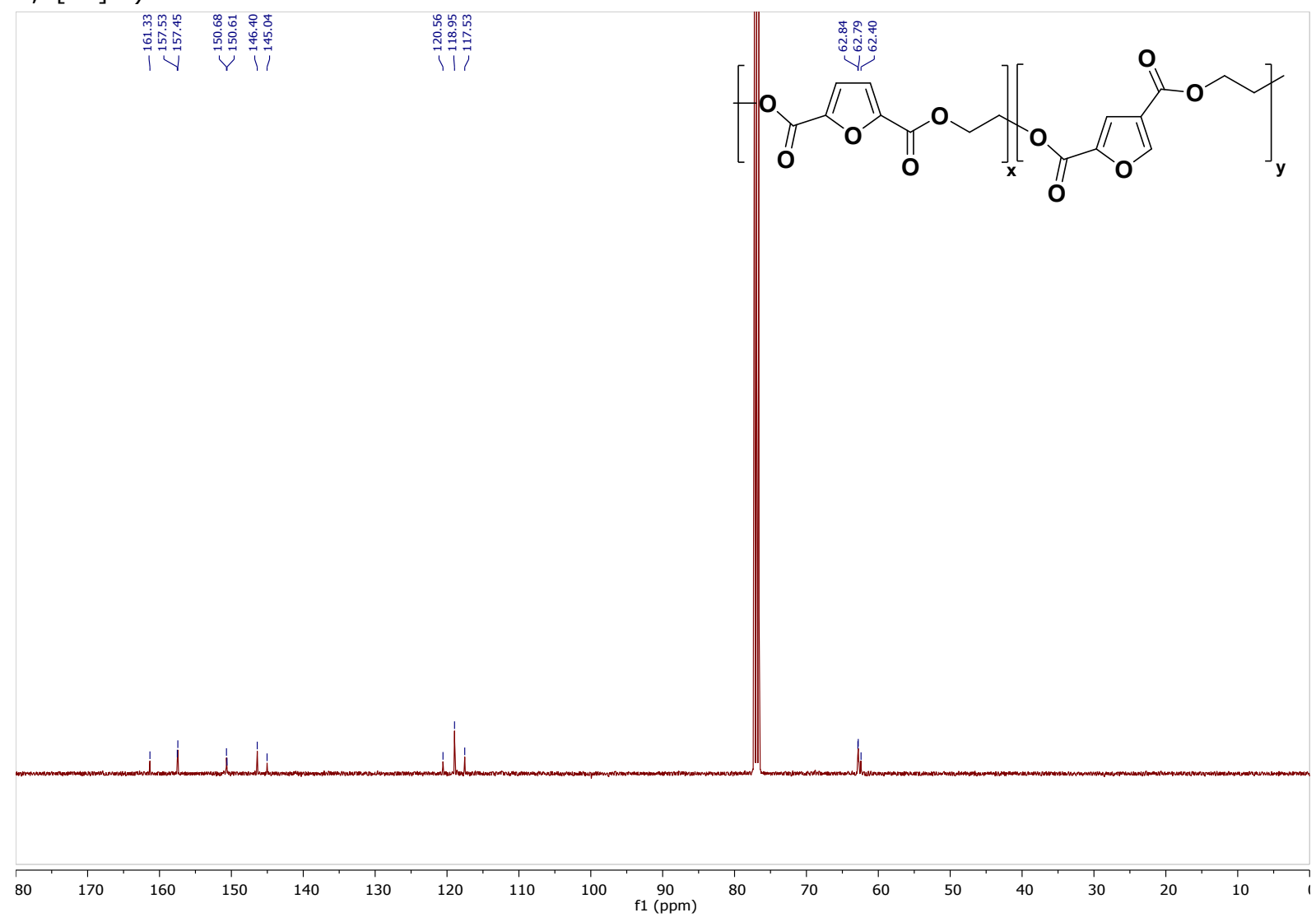

Figure S12: ${ }^{13} \mathrm{C}$ NMR spectrum of Poly(1,2-ethylene-2,5[[50]-2,4[50]-furandicarboxylate) (PE-2,5[50]$2,4[50]-F)$ 


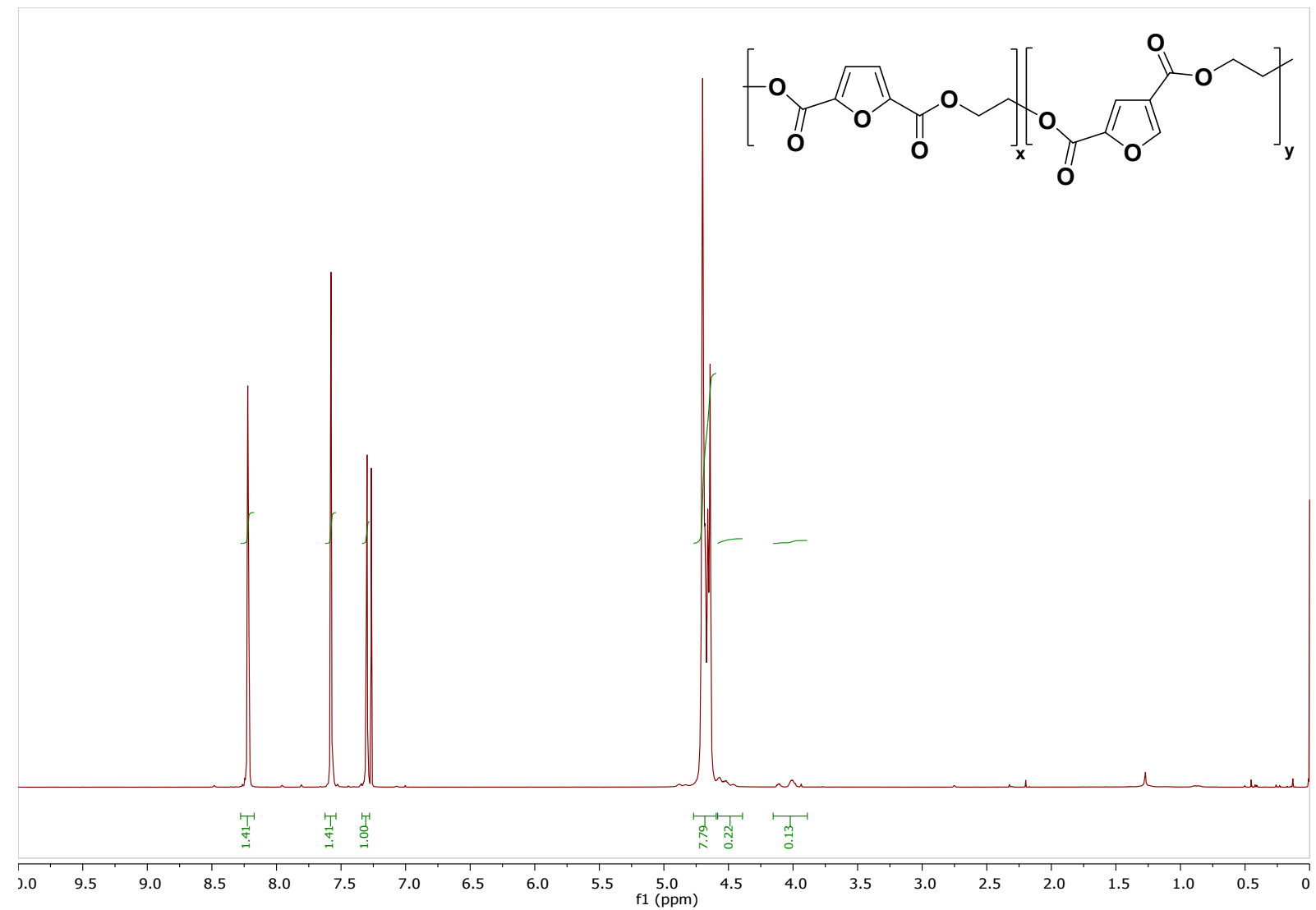

Figure S13: ${ }^{1} \mathrm{H}$ NMR spectrum of Poly(1,2-ethylene-2,5[[25]-2,4[75]-furandicarboxylate) $(\mathrm{PE}-2,5[25]-$ $2,4[75]-\mathrm{F})$

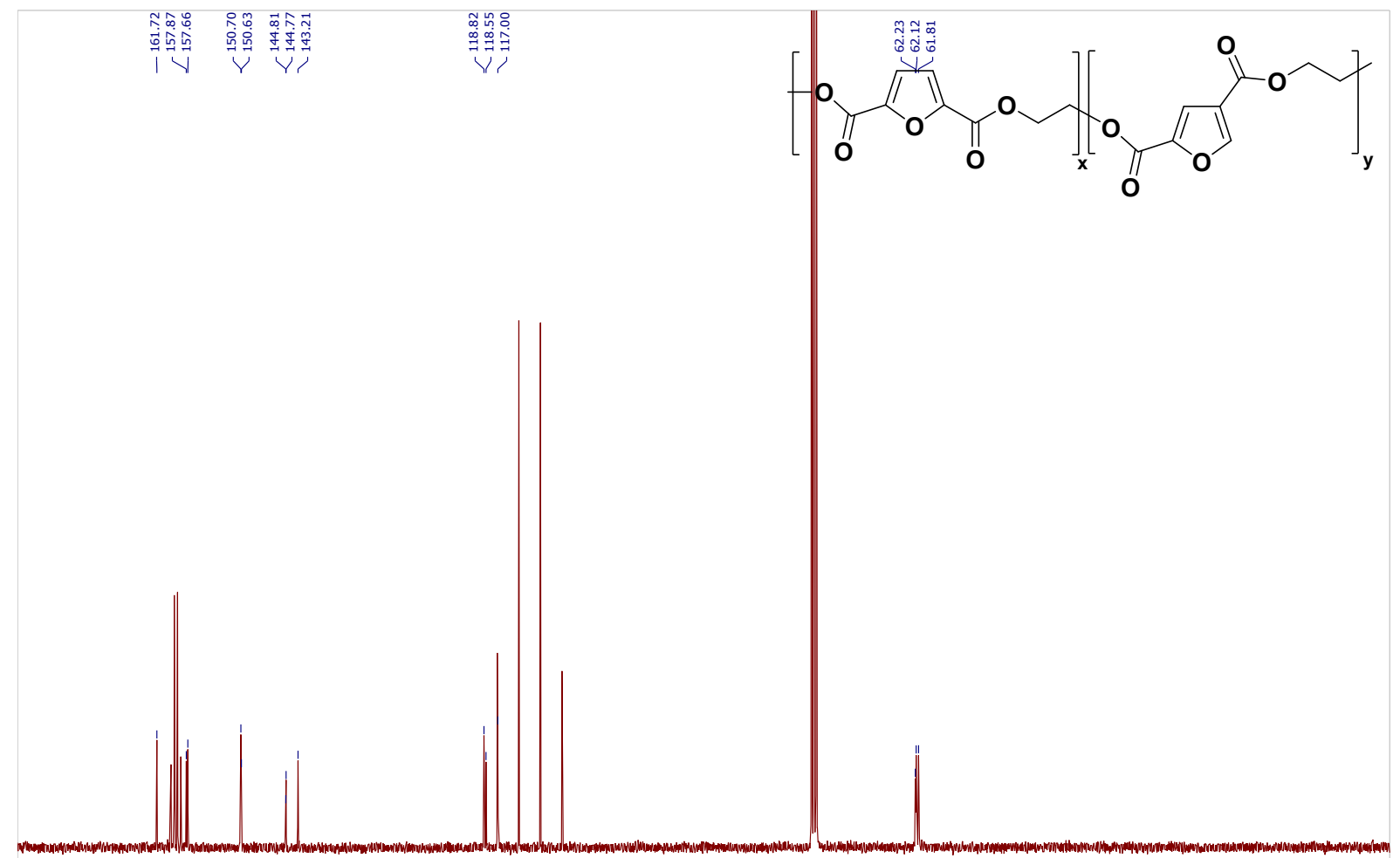

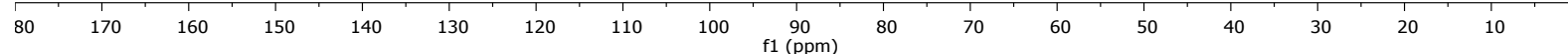

Figure S14: ${ }^{13} \mathrm{C}$ NMR spectrum of Poly(1,2-ethylene-2,5[[25]-2,4[75]-furandicarboxylate) $(\mathrm{PE}-2,5[25]$ 2,4[75]-F) 


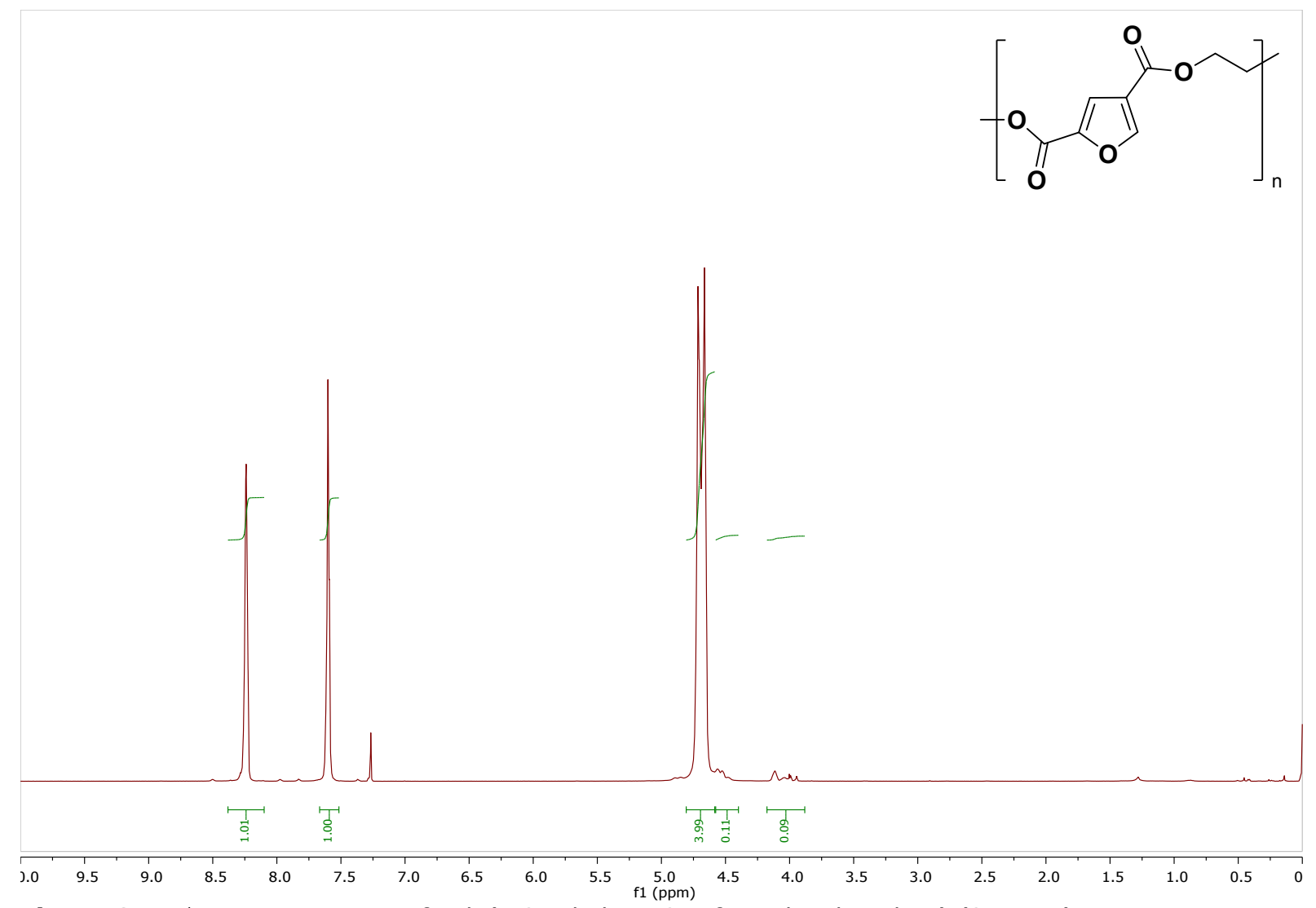

Figure S15: ${ }^{1} \mathrm{H}$ NMR spectrum of Poly(1,2-ethylene-2,4-furandicarboxylate) (2,4-PEF)

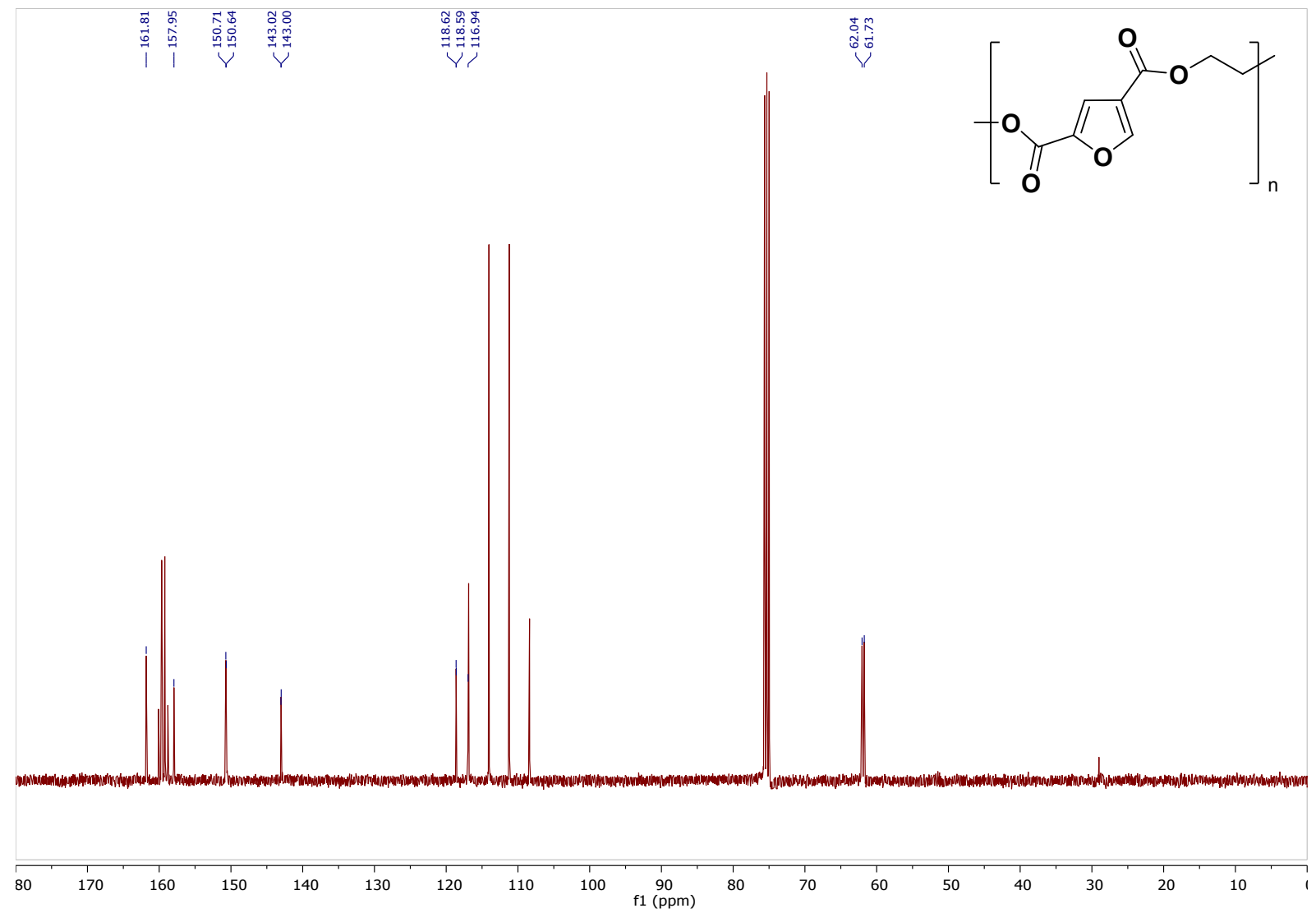

Figure S16: ${ }^{13} \mathrm{C}$ NMR spectrum of Poly(1,2-ethylene-2,4-furandicarboxylate) $(2,4-\mathrm{PEF})$ 


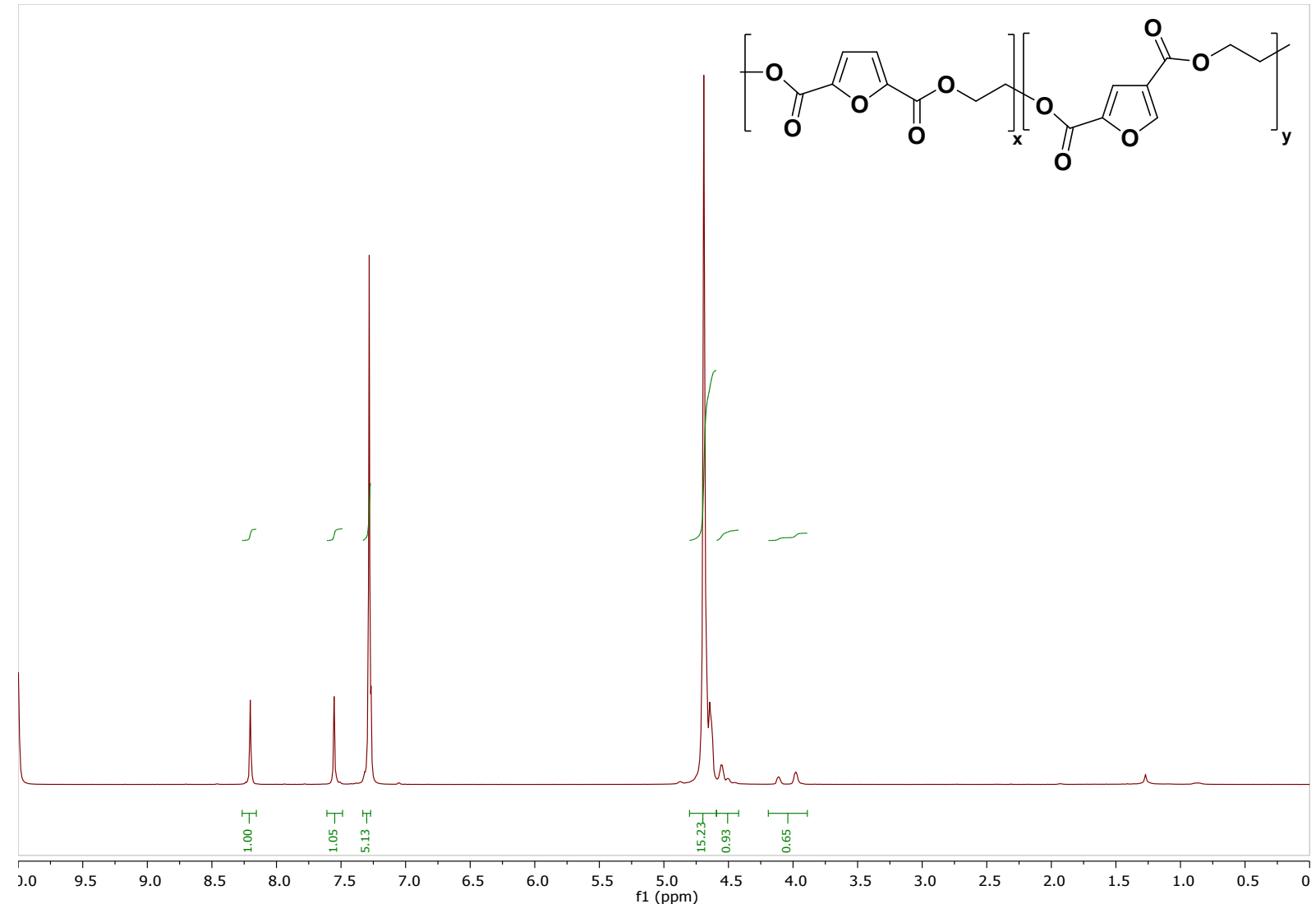

Figure S17: ${ }^{1} \mathrm{H}$ NMR spectrum of PEF-2,5/2,4[H.M-A] (Henkel mixture A)

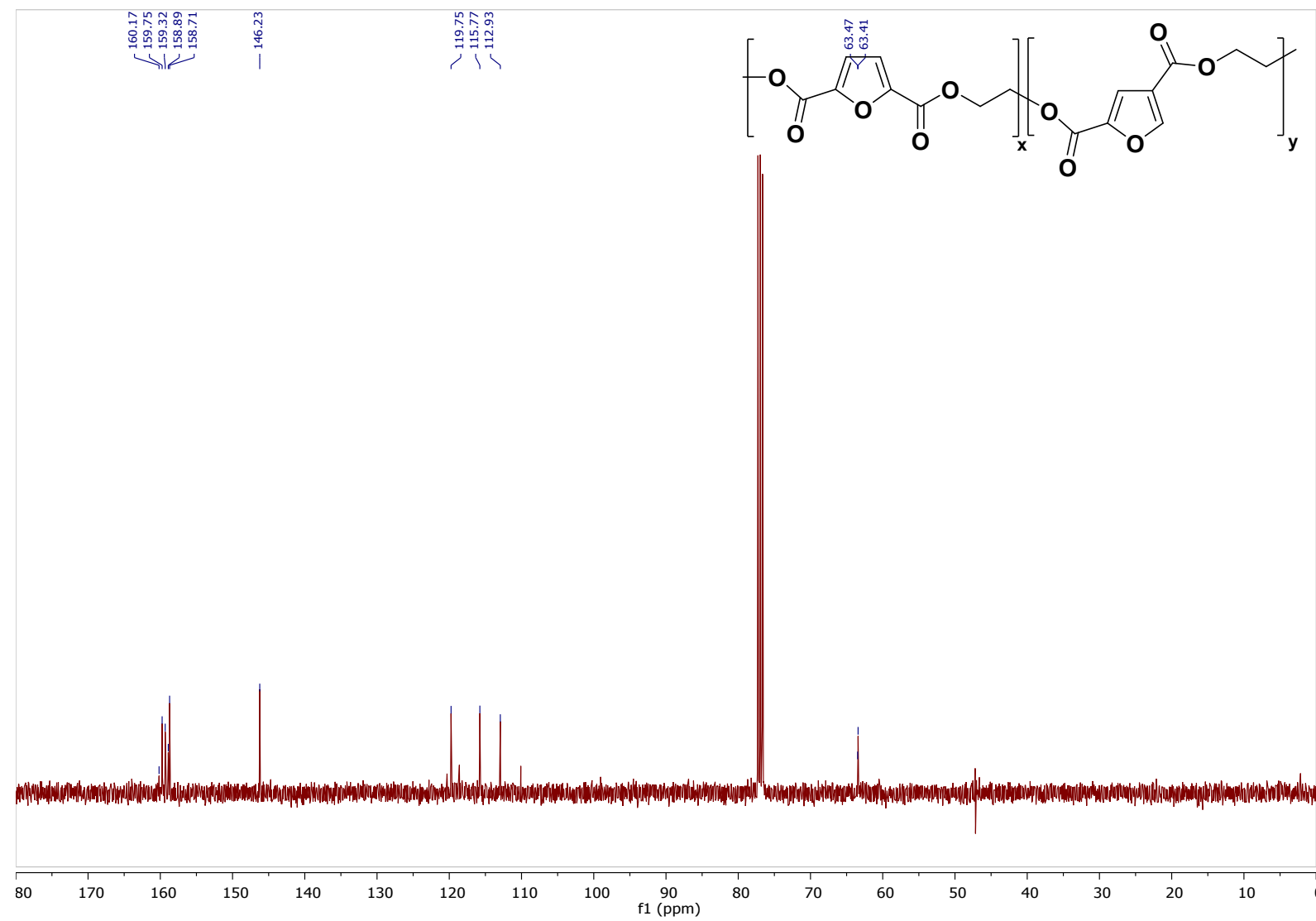

Figure S18: ${ }^{13} \mathrm{C}$ NMR spectrum of PEF-2,5/2,4[H.M-A] (Henkel mixture A) 


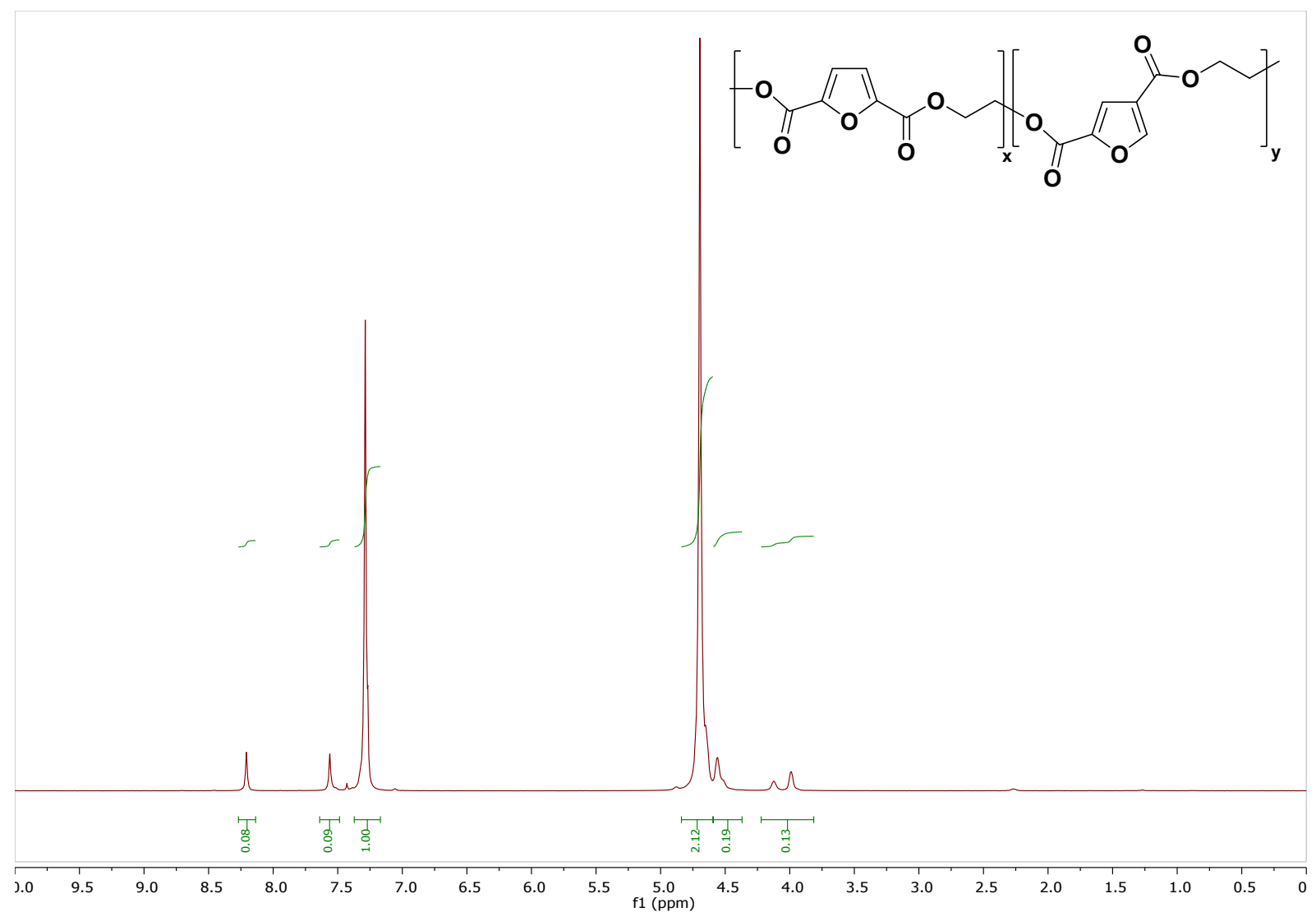

Figure S19: ${ }^{1} \mathrm{H}$ NMR spectrum of PEF-2,5/2,4[H.M-B] (Henkel mixture $B$ )

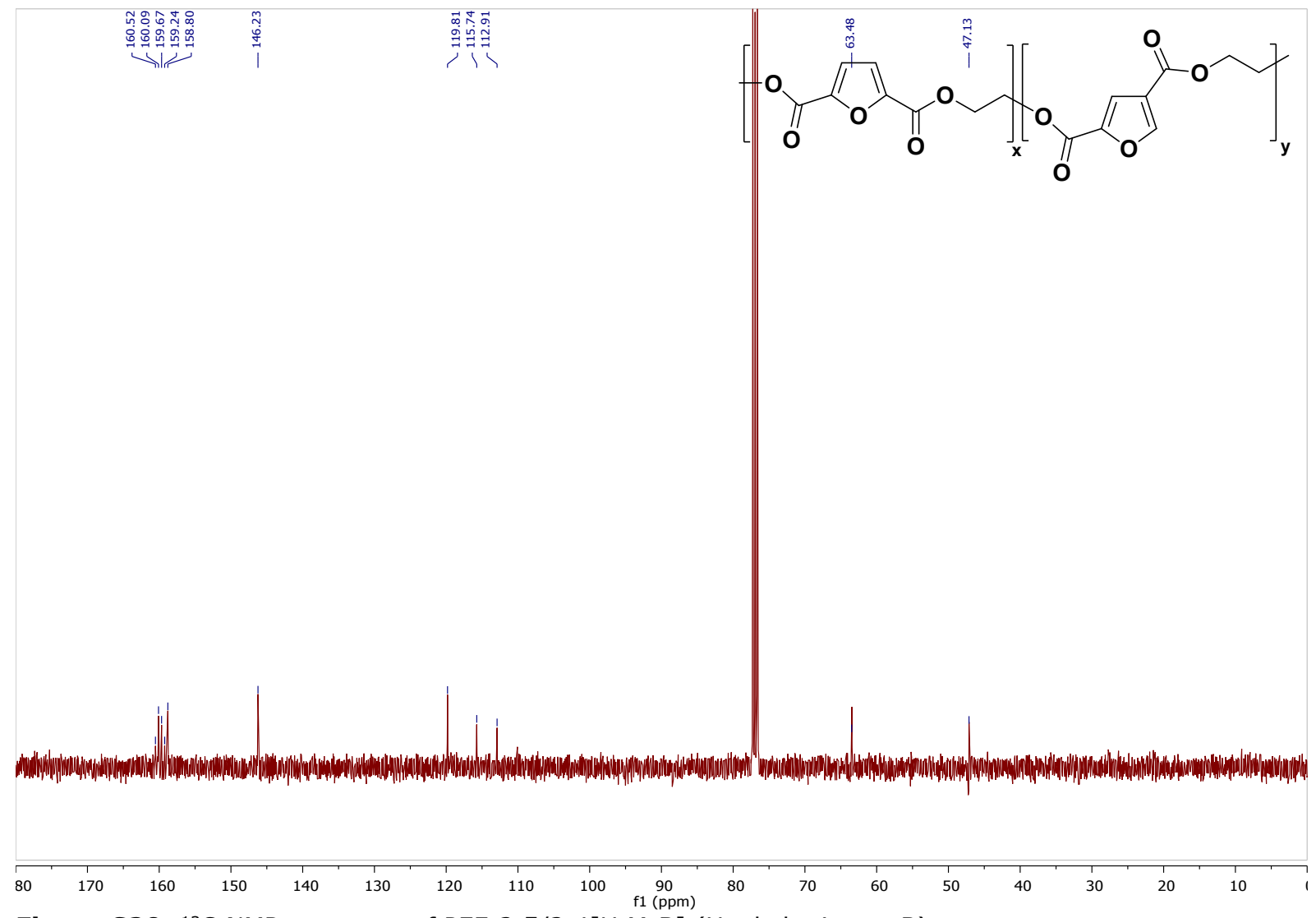

Figure S20: ${ }^{13} \mathrm{C}$ NMR spectrum of PEF-2,5/2,4[H.M-B] (Henkel mixture B) 


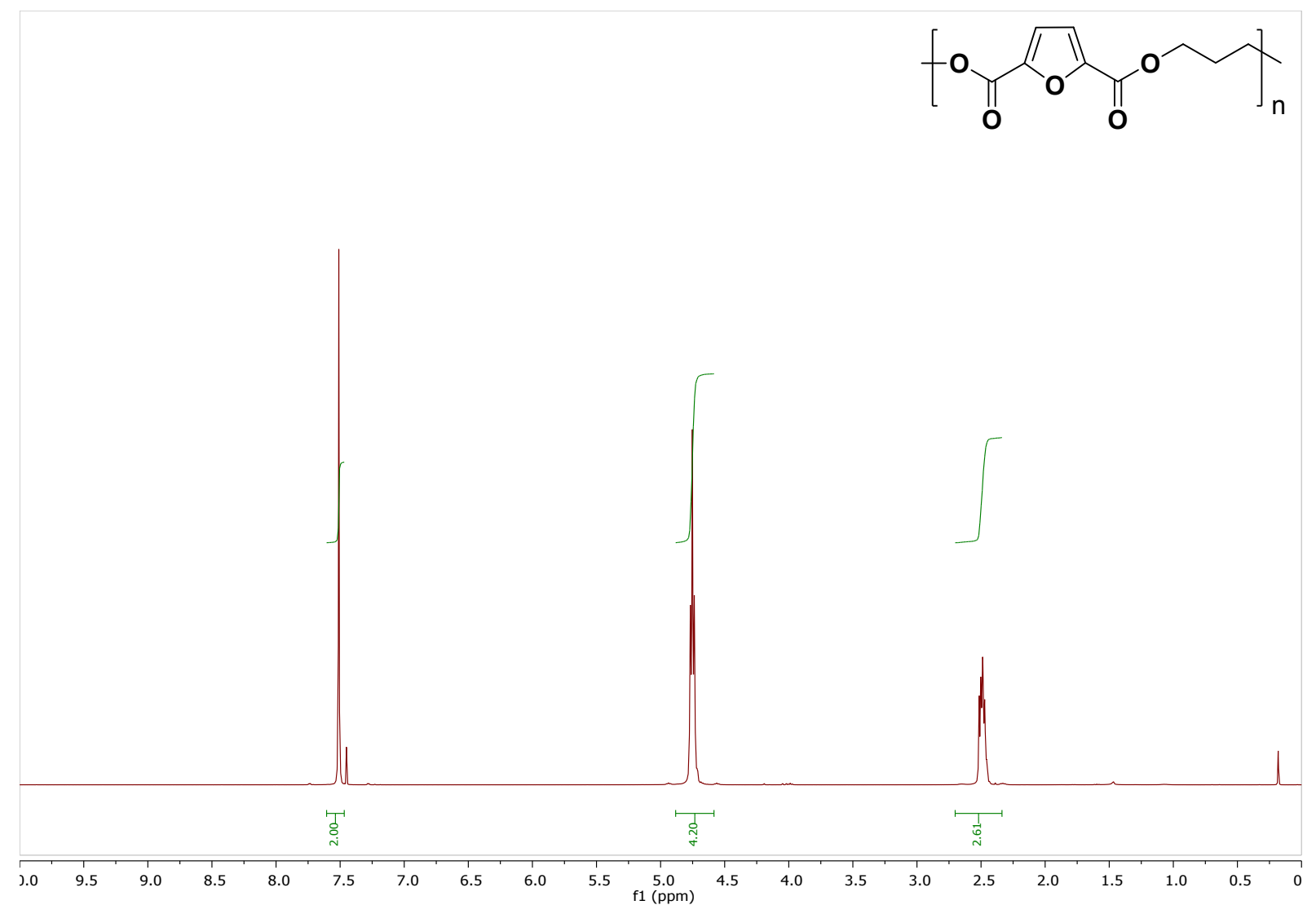

Figure S21: ${ }^{1} \mathrm{H}$ NMR spectrum of Poly(1,3-propylene-2,5-furandicarboxylate) (2,5-PPF)

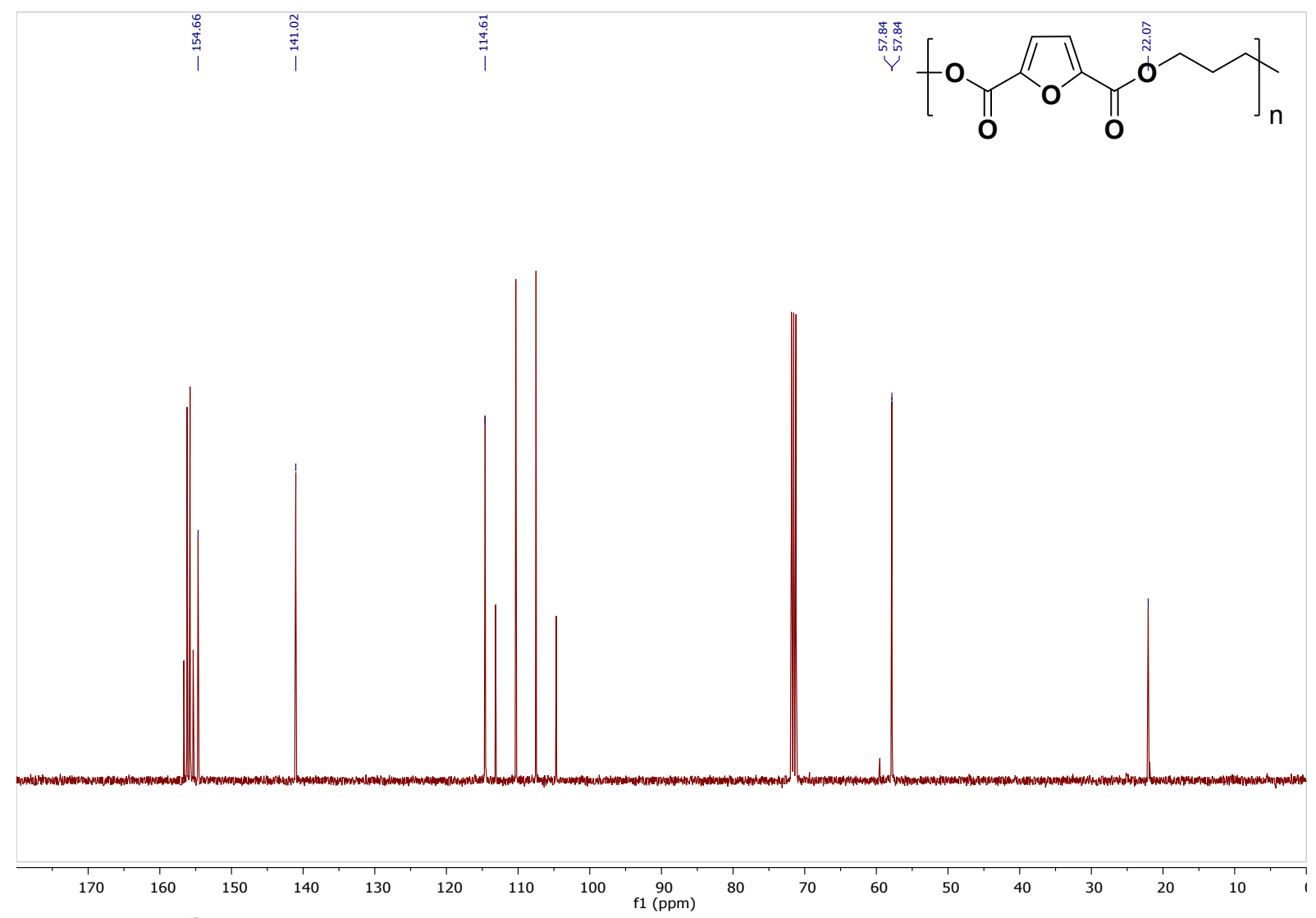

Figure S22: ${ }^{13} \mathrm{C}$ NMR spectrum of Poly(1,3-propylene-2,5-furandicarboxylate) (2,5-PPF) 


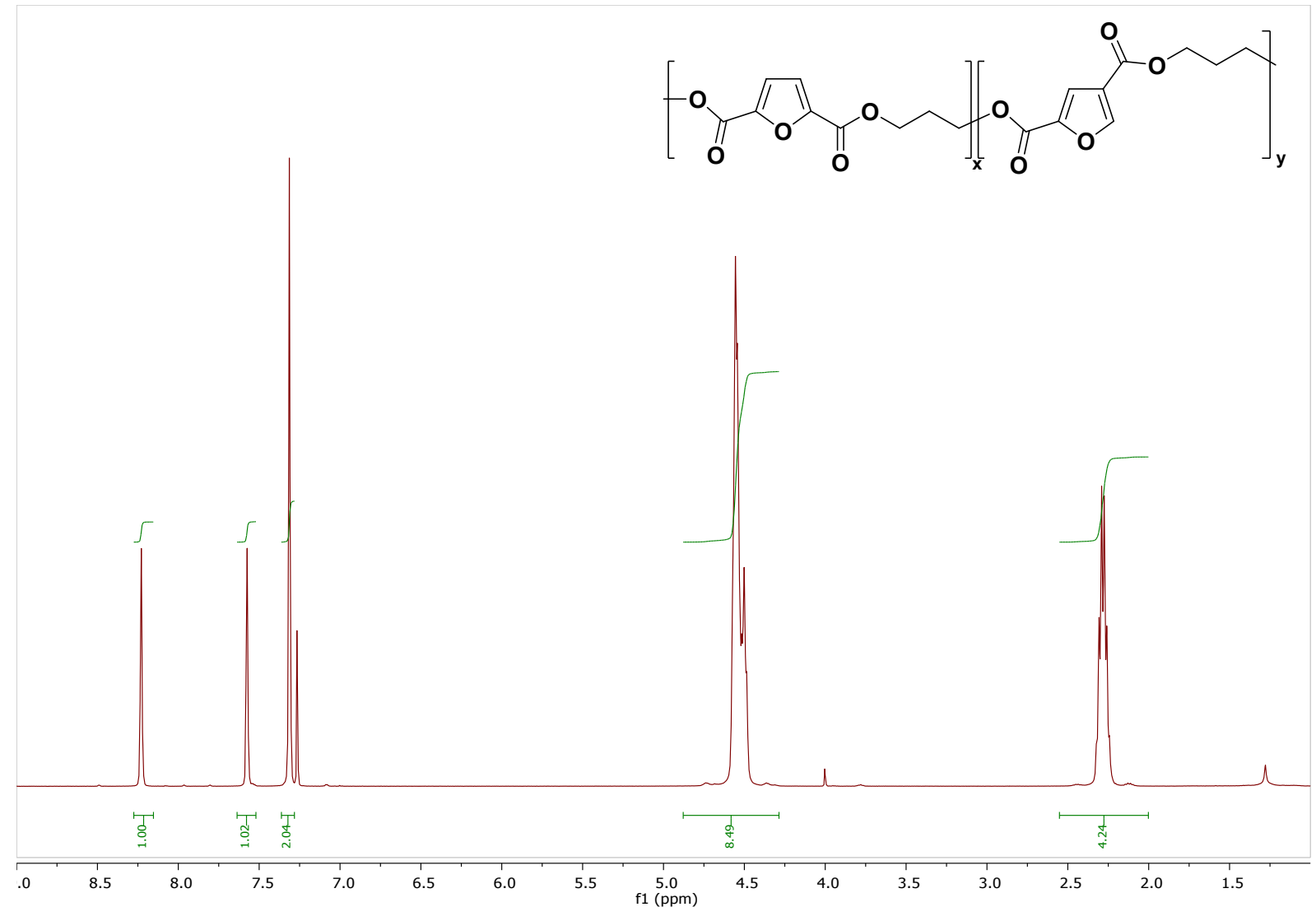

Figure S23: ${ }^{1} \mathrm{H}$ NMR spectrum of Poly(1,3-propylene-2,5[50]-2,4[50]-furandicarboxylate) (PP-2,5[50]$2,4[50]-F)$

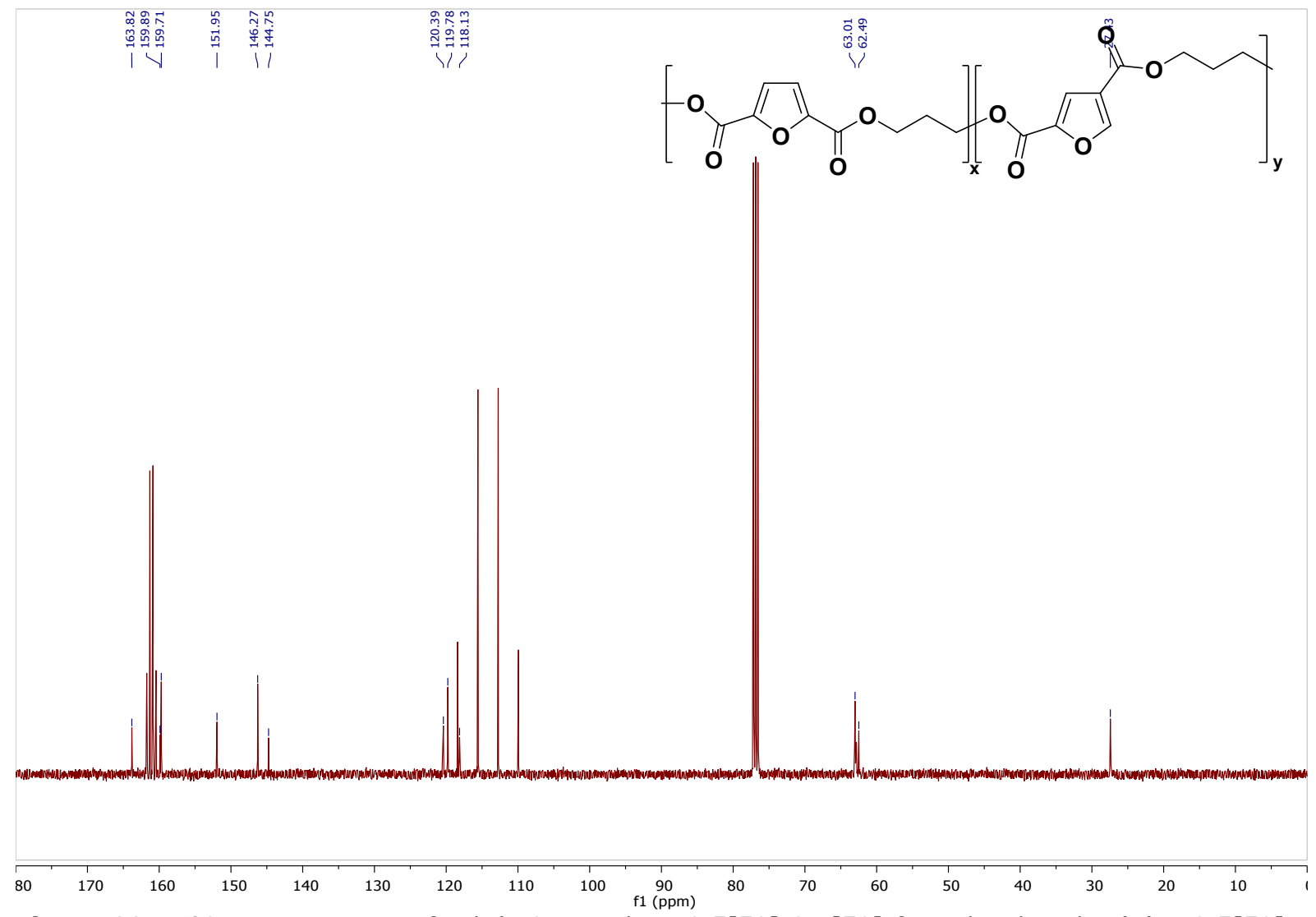

Figure S24: ${ }^{13} \mathrm{C}$ NMR spectrum of Poly(1,3-propylene-2,5[50]-2,4[50]-furandicarboxylate) (PP-2,5[50]$2,4[50]-F)$ 


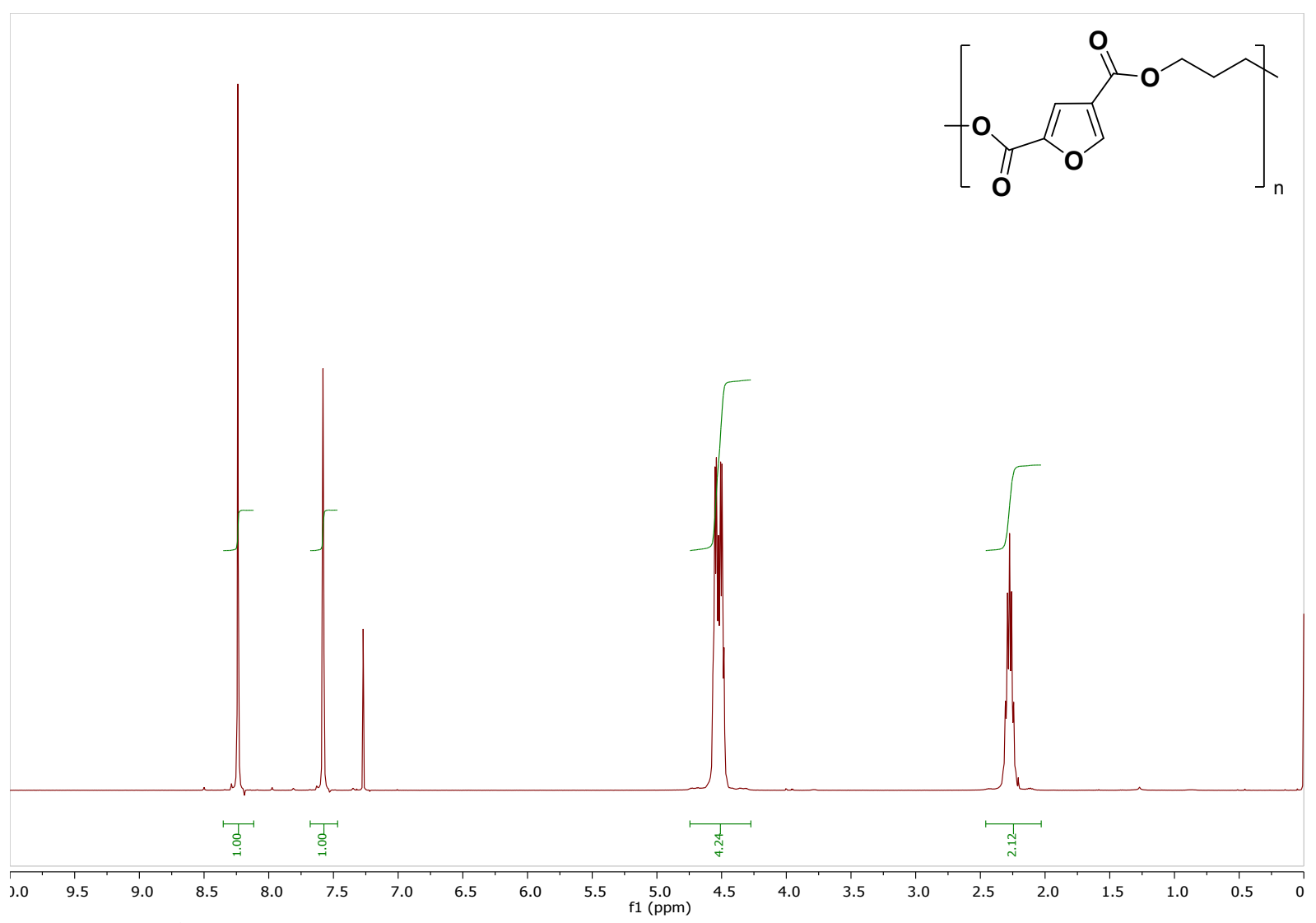

Figure S25: ${ }^{1} \mathrm{H}$ NMR spectrum of Poly(1,3-propylene-2,4-furandicarboxylate) (2,4-PPF)

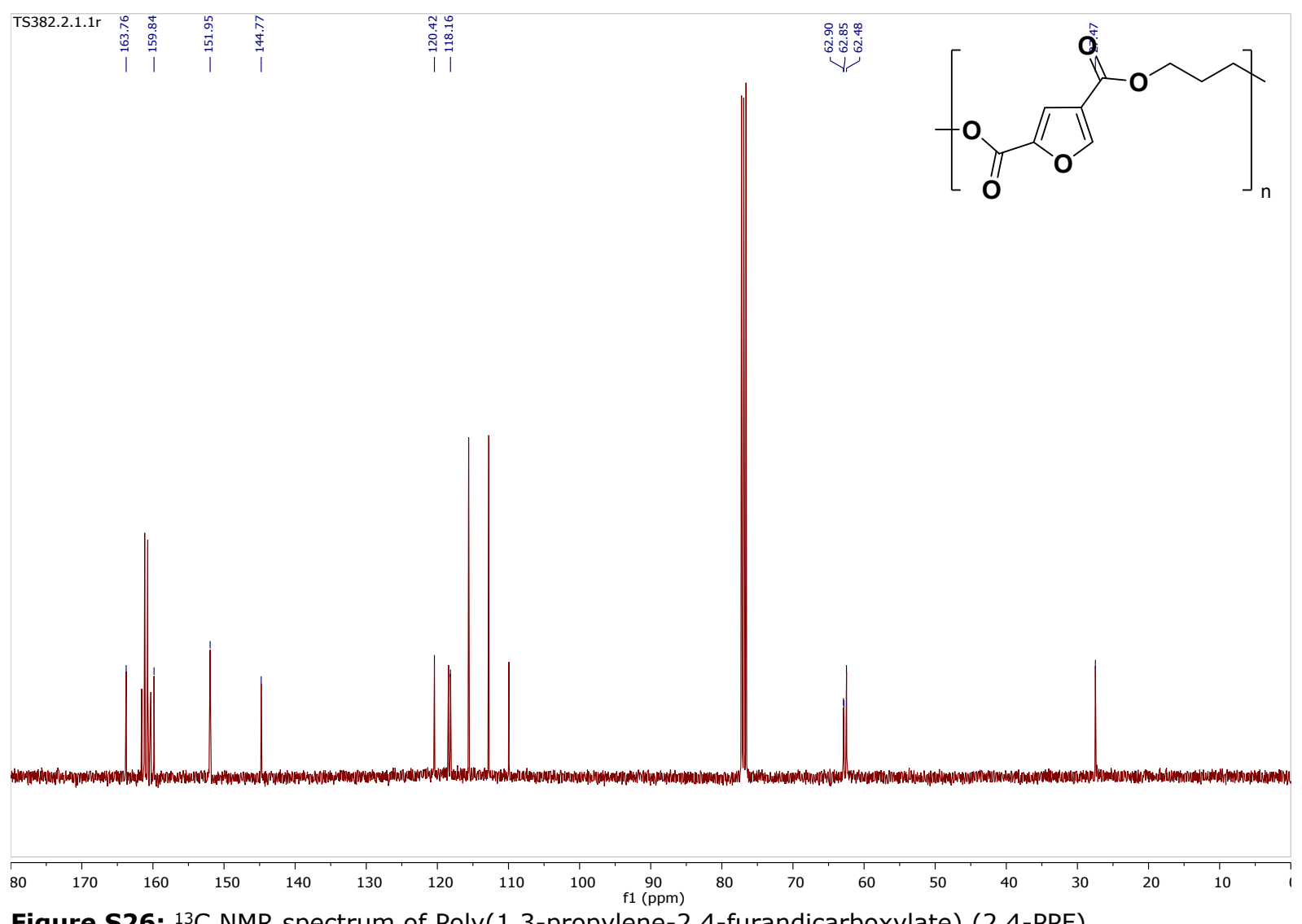

Figure S26: ${ }^{13} \mathrm{C}$ NMR spectrum of Poly(1,3-propylene-2,4-furandicarboxylate) (2,4-PPF)

S16 


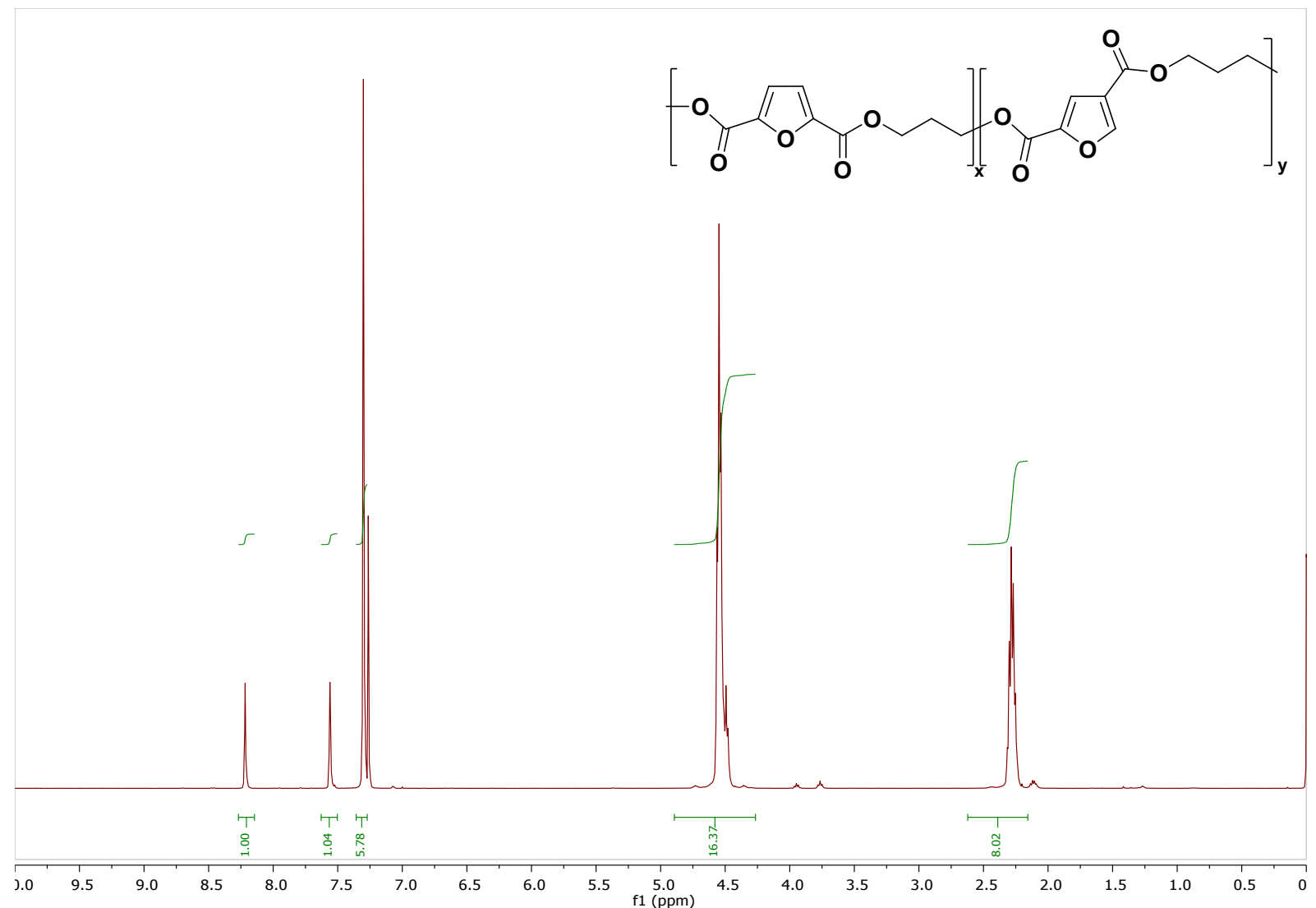

Figure S27: ${ }^{1} \mathrm{H}$ NMR spectrum of PPF-2,5/2,4[H.M-A] (Henkel mixture A)

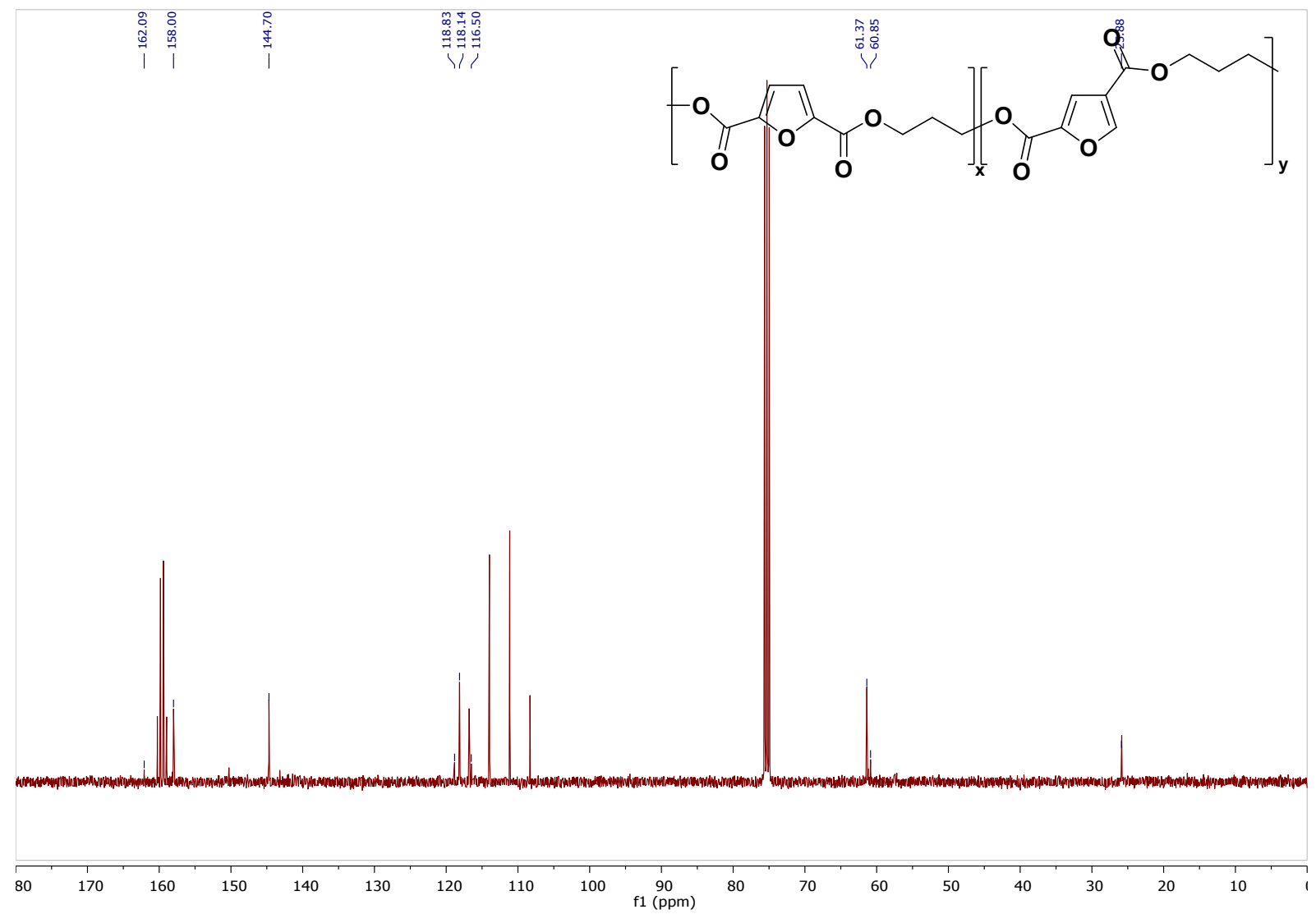

Figure S28: ${ }^{13} \mathrm{C}$ NMR spectrum of PPF-2,5/2,4[H.M-A] (Henkel mixture A) 


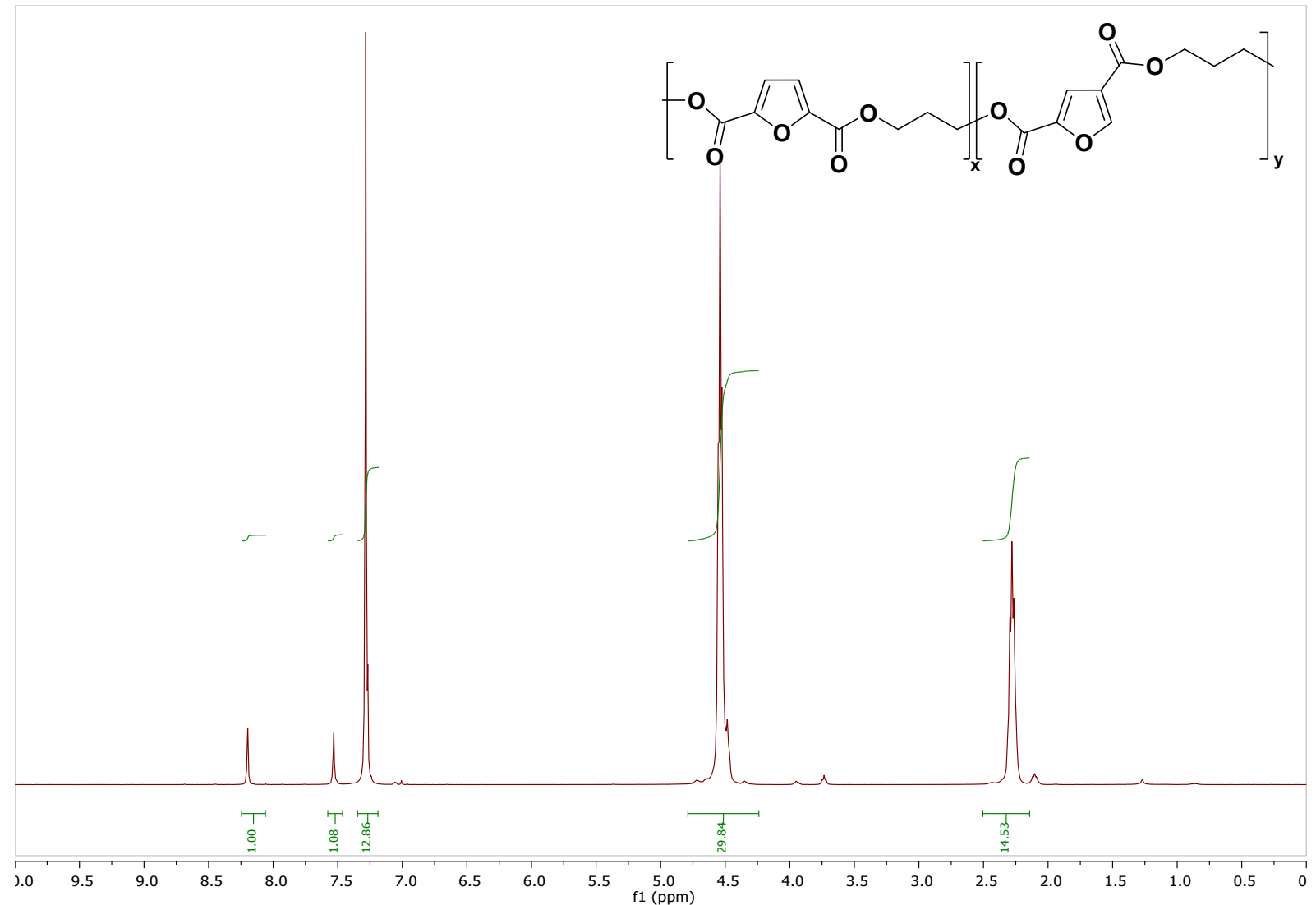

Figure S29: ${ }^{1} \mathrm{H}$ NMR spectrum of PPF-2,5/2,4[H.M-B] (Henkel mixture $B$ )

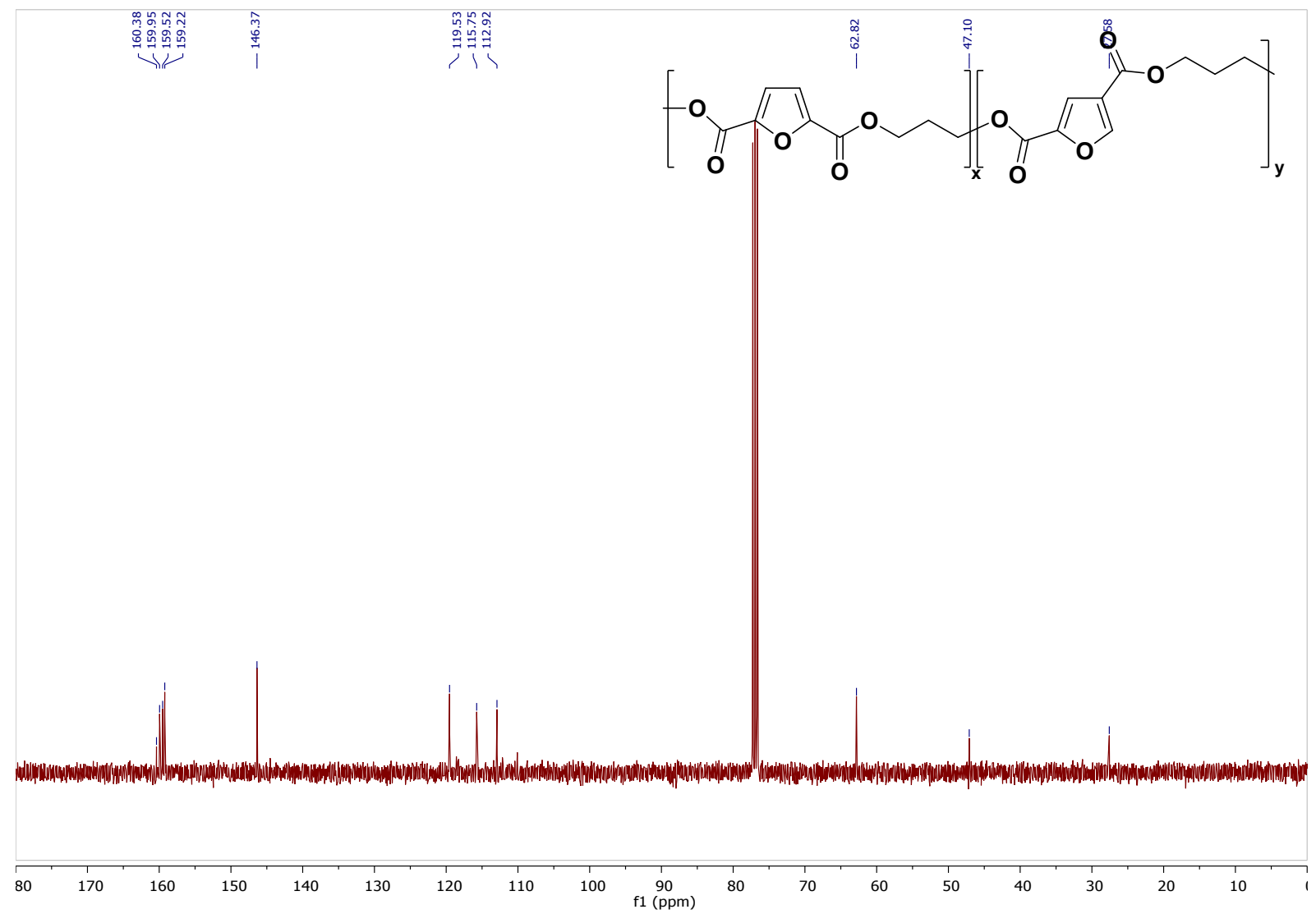

Figure S30: ${ }^{13} \mathrm{C}$ NMR spectrum of PPF-2,5/2,4[H.M-B] (Henkel mixture B) 


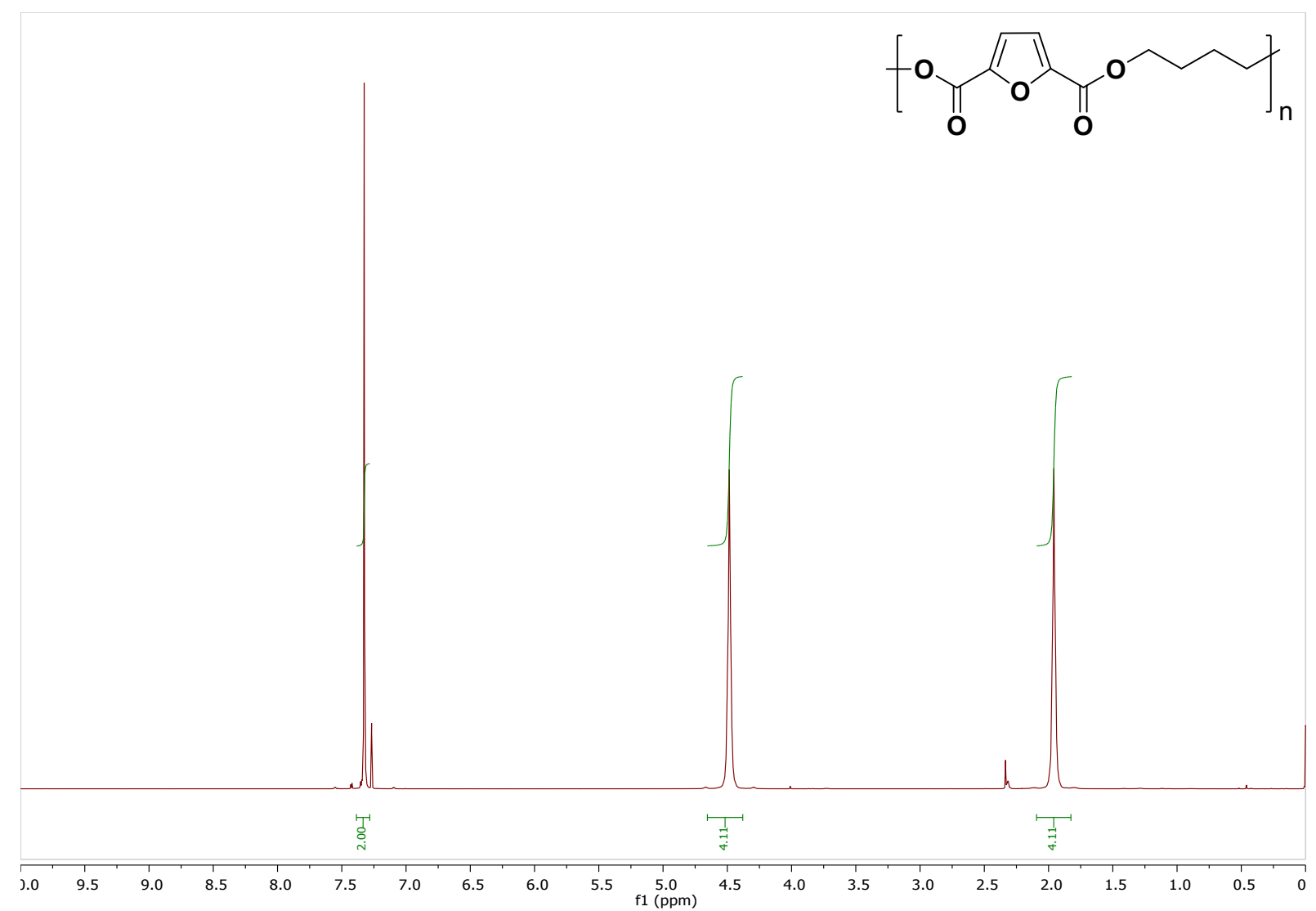

Figure S31: ${ }^{1} \mathrm{H}$ NMR spectrum of Poly(1,4-butylene-2,5-furandicarboxylate) (2,5-PBF)

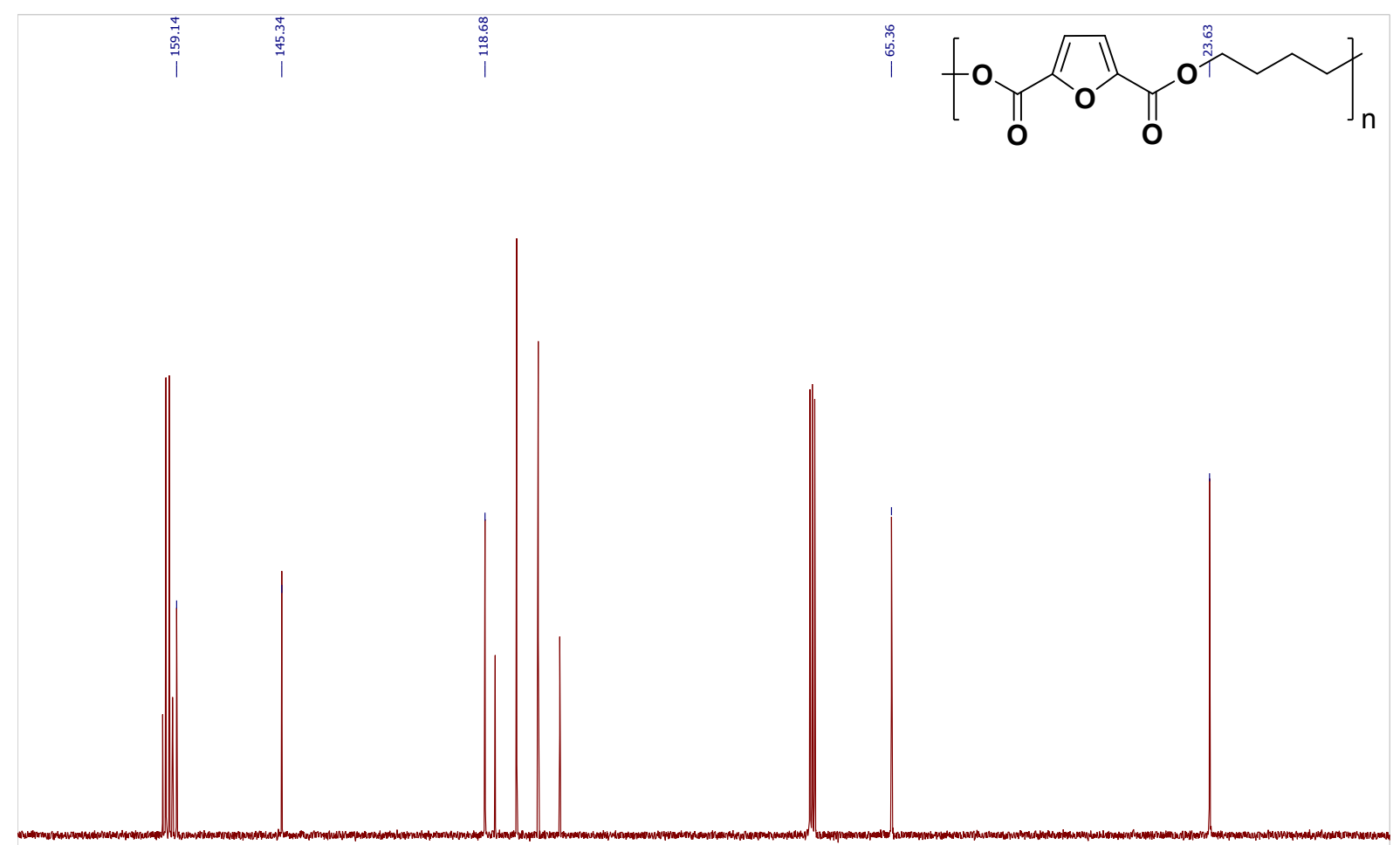

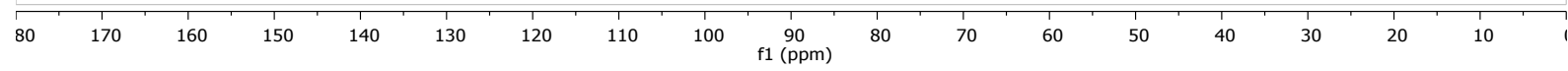

Figure S32: ${ }^{13} \mathrm{C}$ NMR spectrum of Poly(1,4-butylene-2,5-furandicarboxylate) (2,5-PBF) 


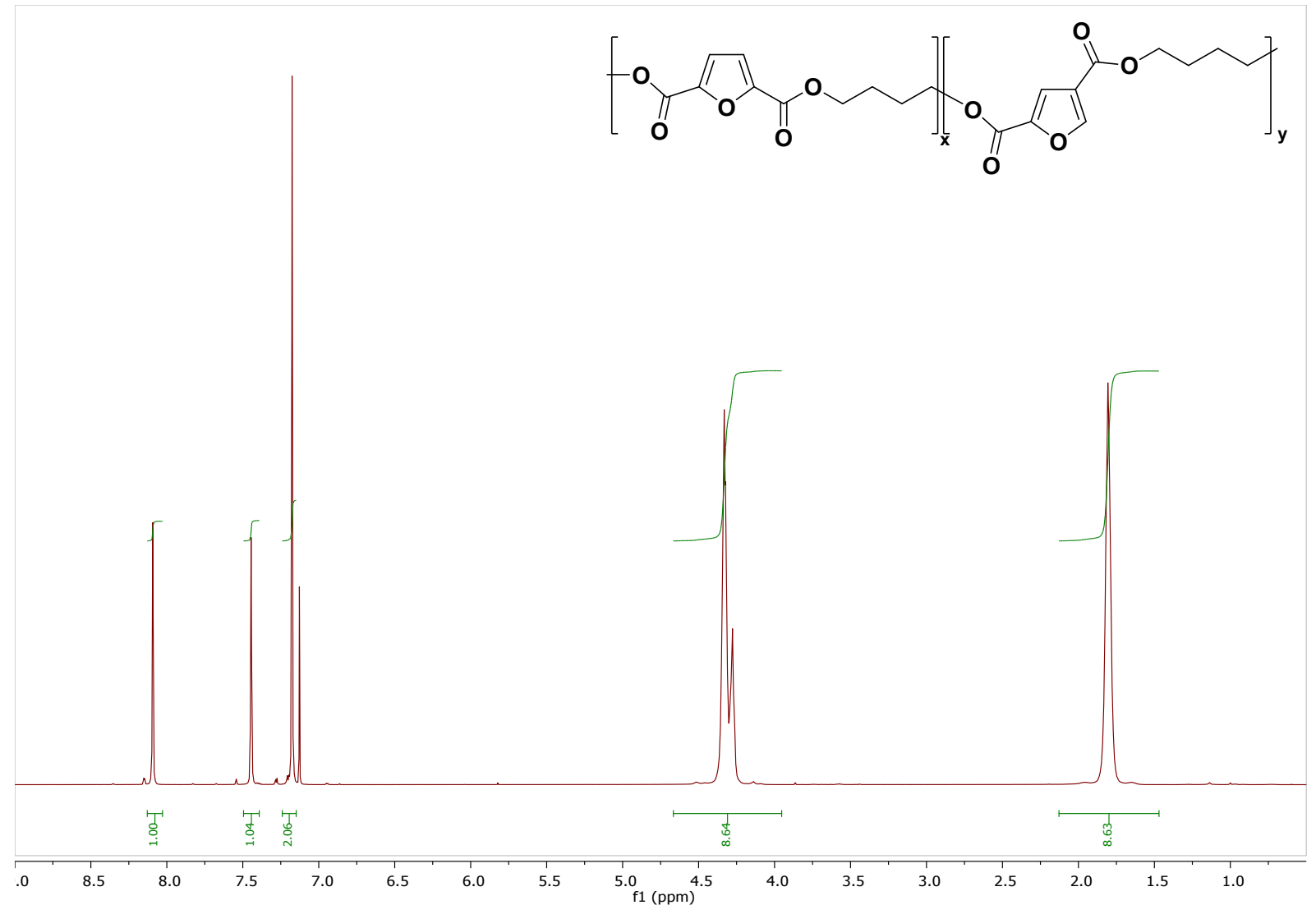

Figure S33: ${ }^{1} \mathrm{H}$ NMR spectrum of Poly(1,4-butylene-2,5[50]-2,4[50]-furandicarboxylate) (PB-2,5[50]$2,4[50]-F)$

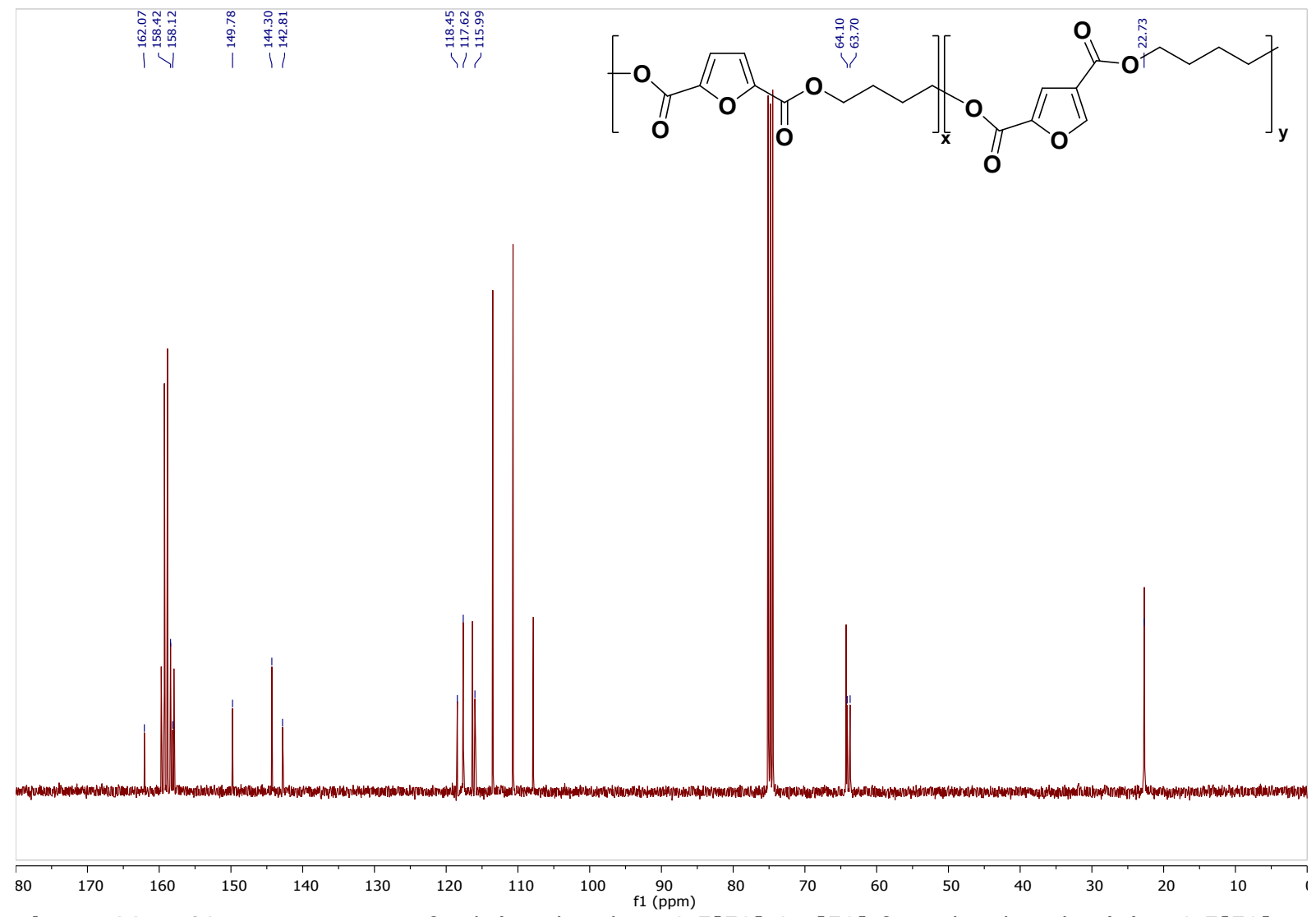

Figure S34: ${ }^{13} \mathrm{C}$ NMR spectrum of Poly(1,4-butylene-2,5[50]-2,4[50]-furandicarboxylate) (PB-2,5[50]$2,4[50]-F)$ 


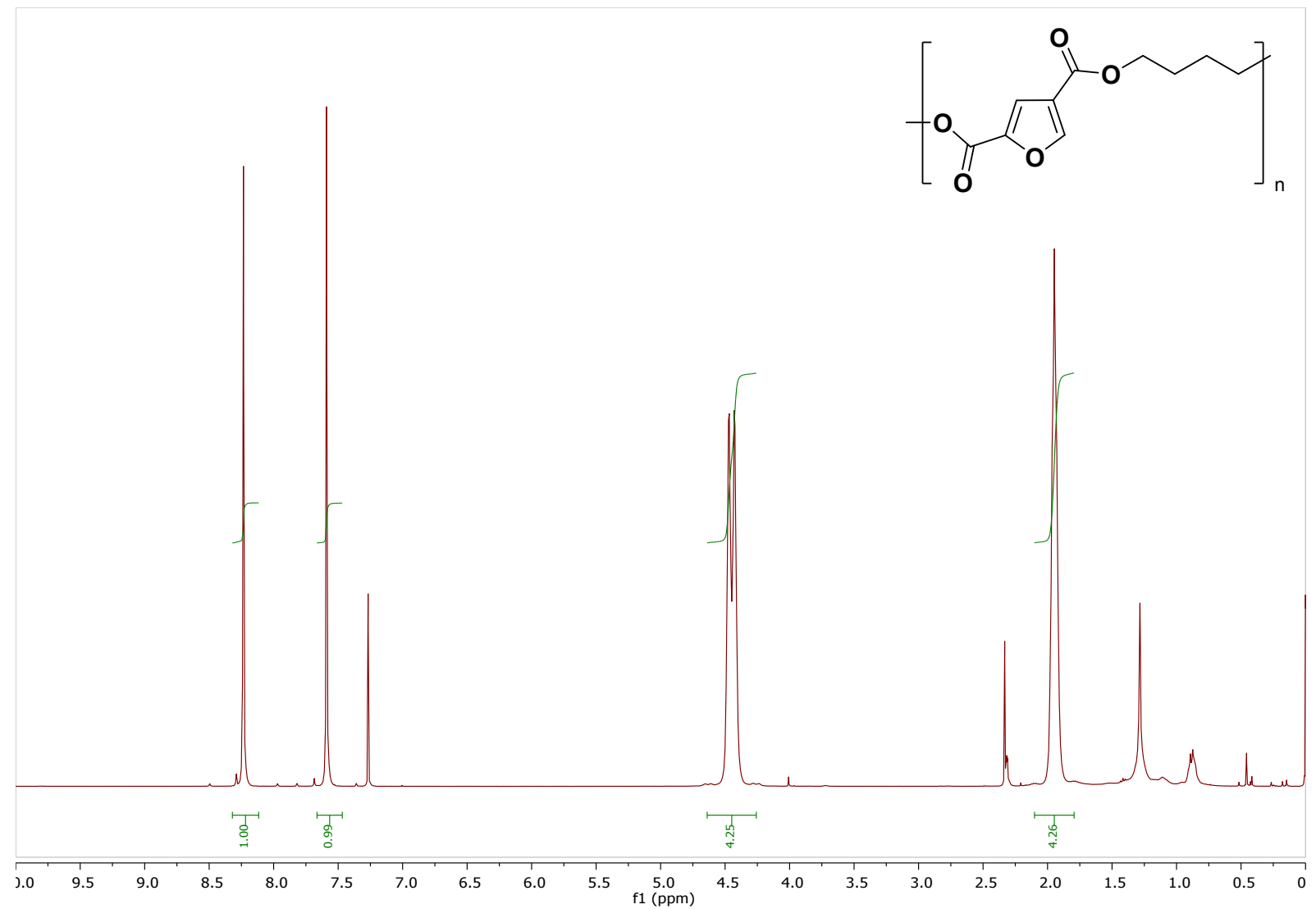

Figure S35: ${ }^{1} \mathrm{H}$ NMR spectrum of Poly(1,4-butylene-2,4-furandicarboxylate) (2,4-PBF)

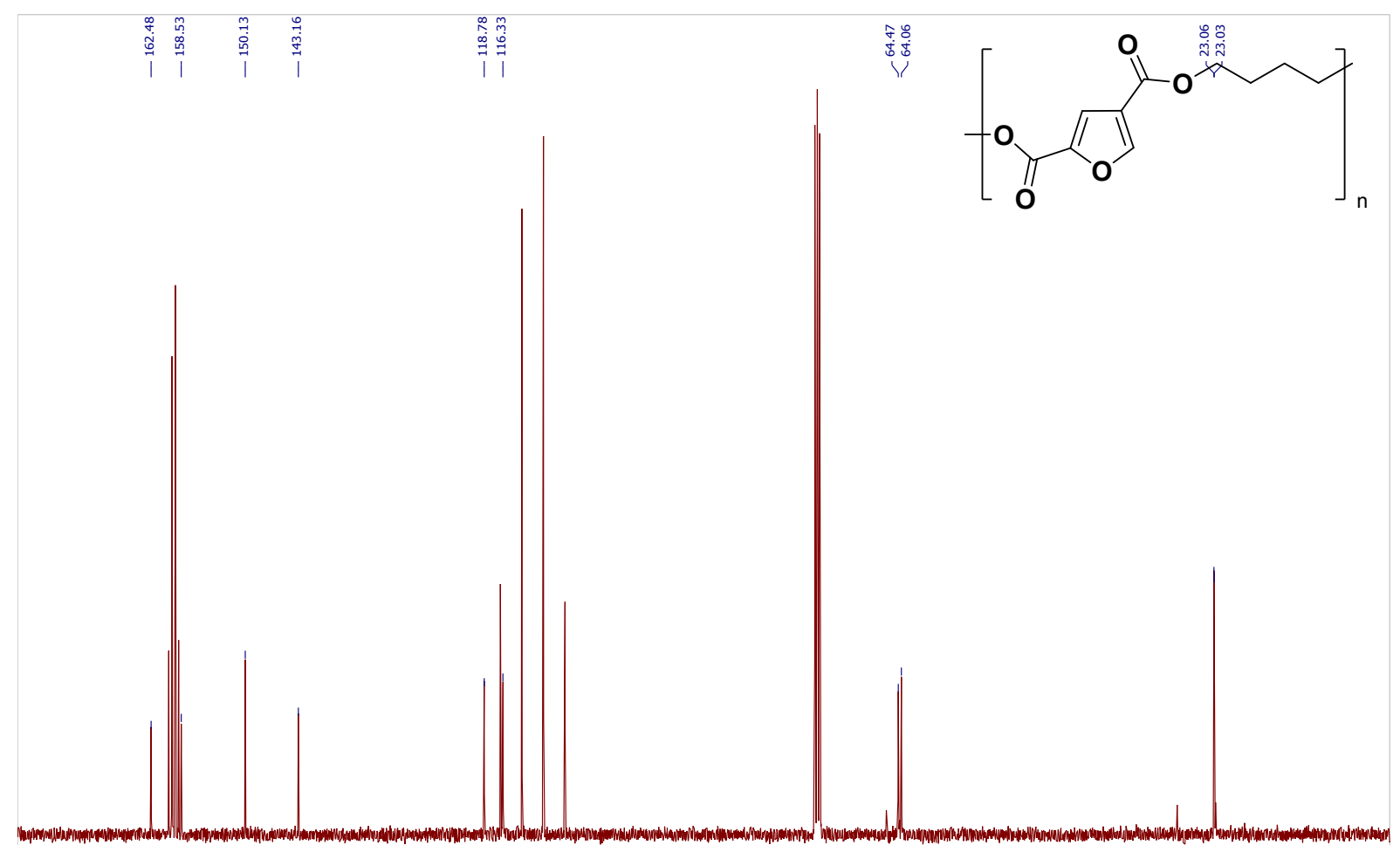

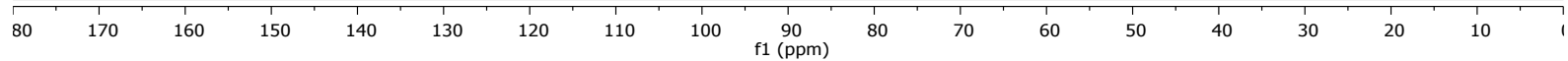

Figure S36: ${ }^{13} \mathrm{C}$ NMR spectrum of Poly(1,4-butylene-2,4-furandicarboxylate) (2,4-PBF) 

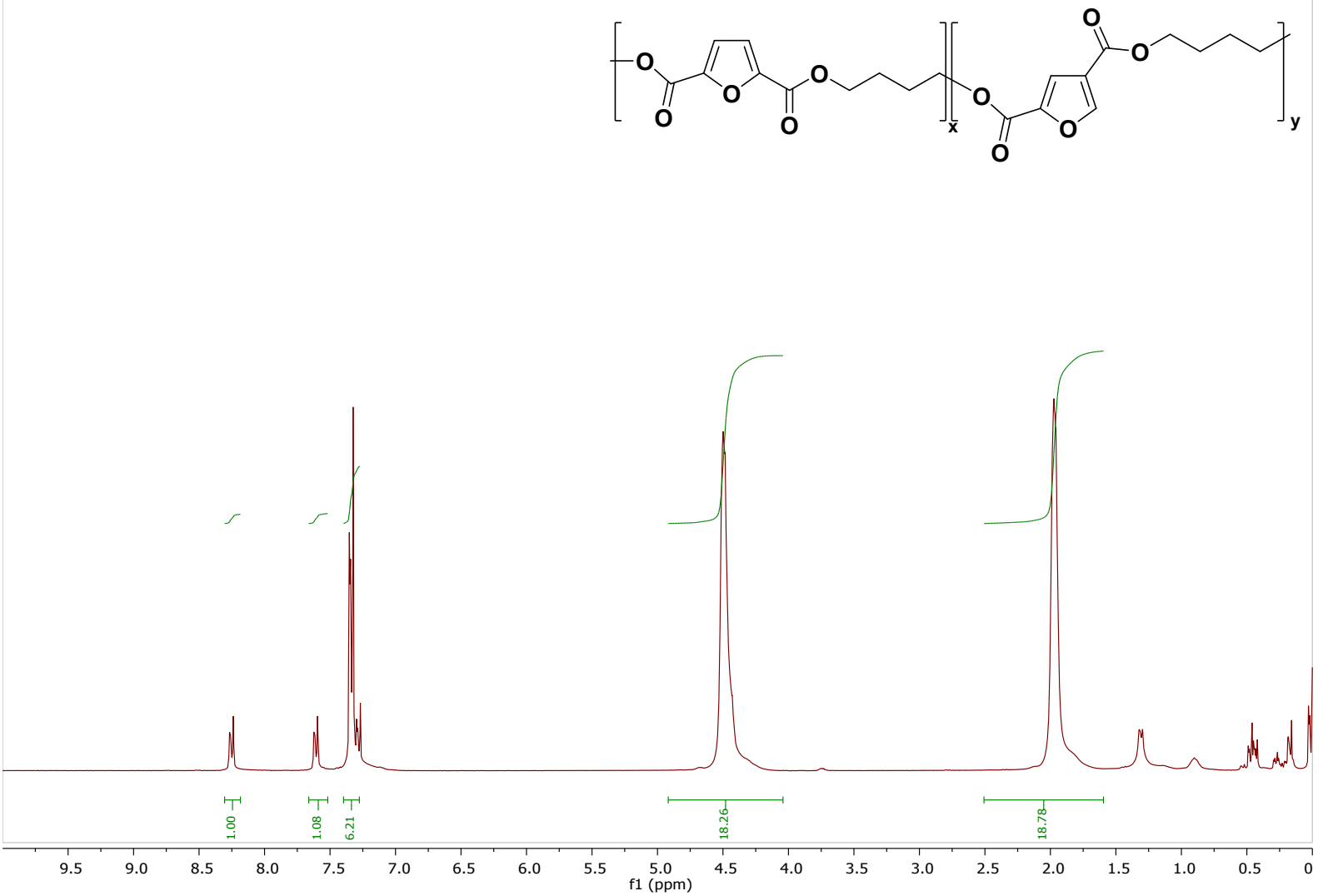

Figure S37: ${ }^{1} \mathrm{H}$ NMR spectrum of PBF-2,5/2,4[H.M-A] (Henkel mixture A)

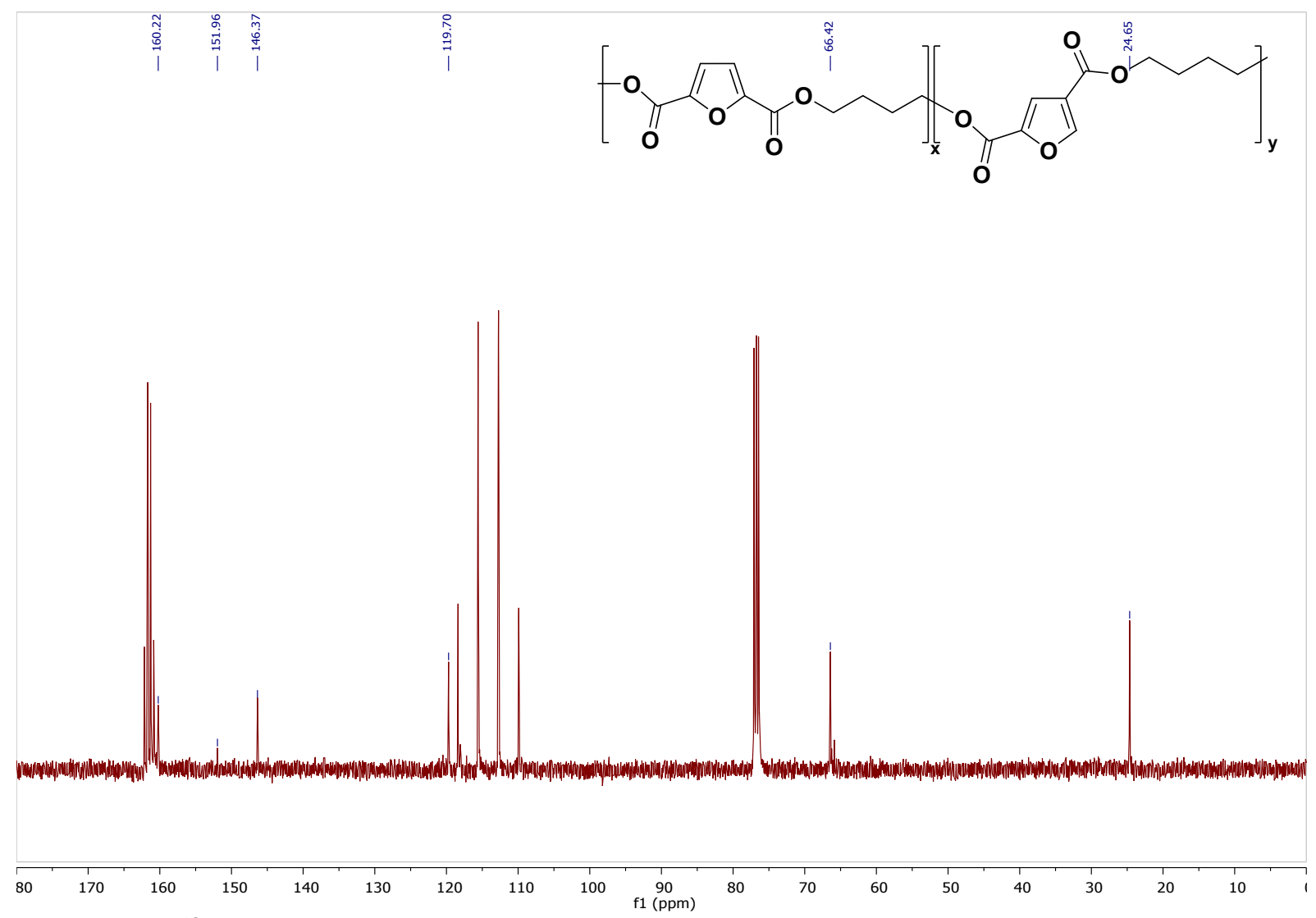

Figure S38: ${ }^{13} \mathrm{C}$ NMR spectrum of PBF-2,5/2,4[H.M-A] (Henkel mixture A) 


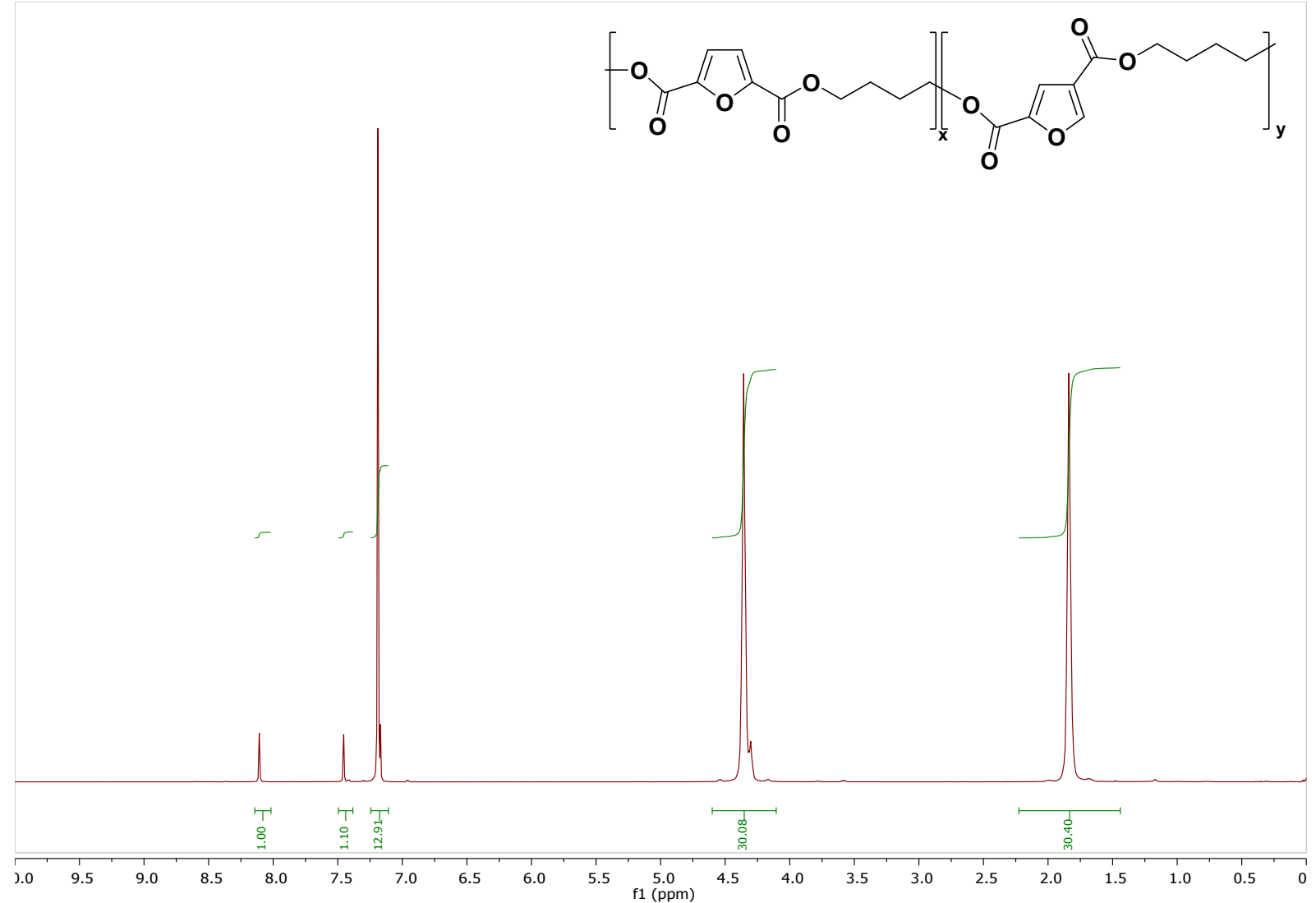

Figure S39: ${ }^{1} \mathrm{H}$ NMR spectrum of PBF-2,5/2,4[H.M-B] (Henkel mixture $B$ )
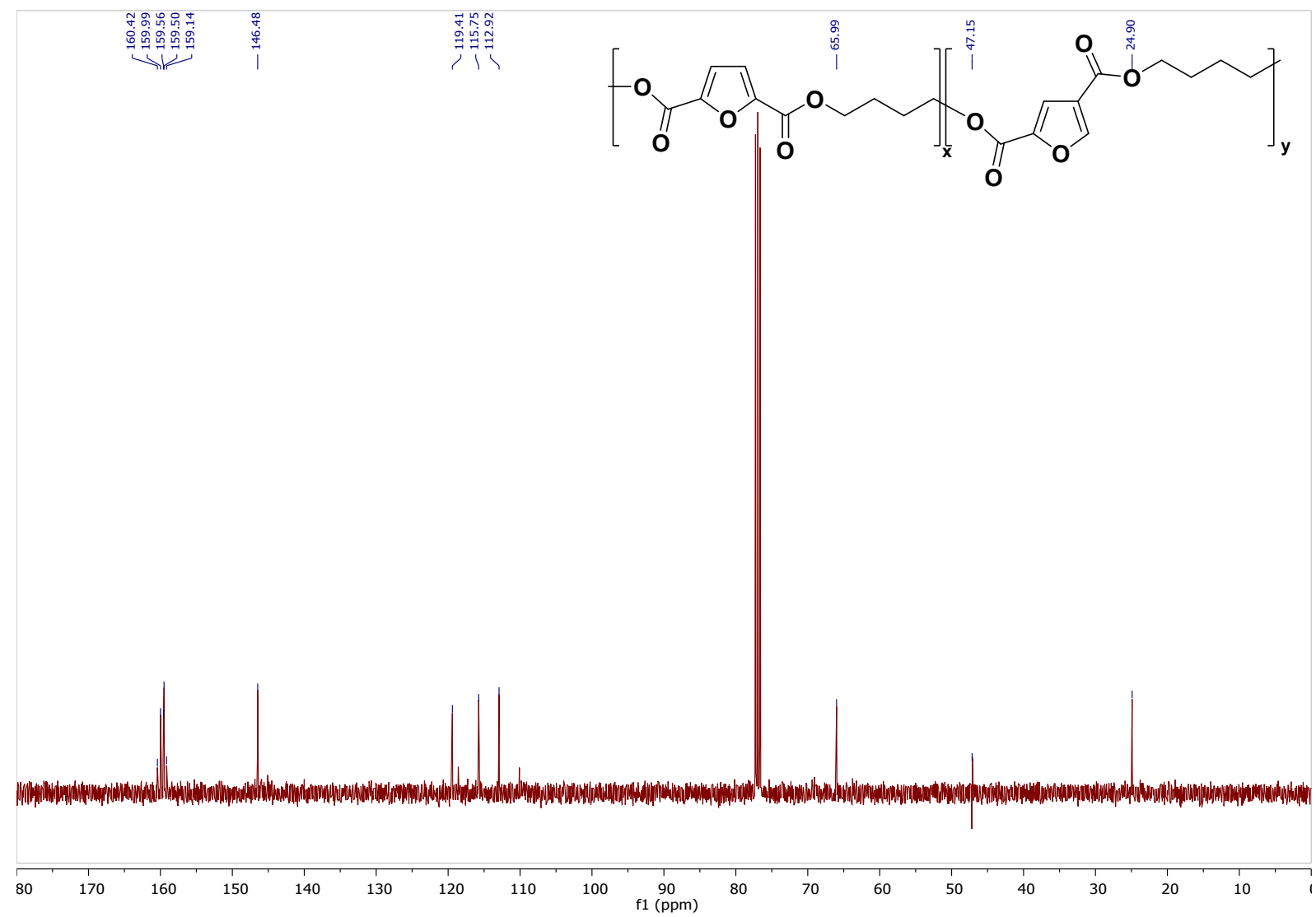

Figure S40: ${ }^{13} \mathrm{C}$ NMR spectrum of PBF-2,5/2,4[H.M-B] (Henkel mixture B) 


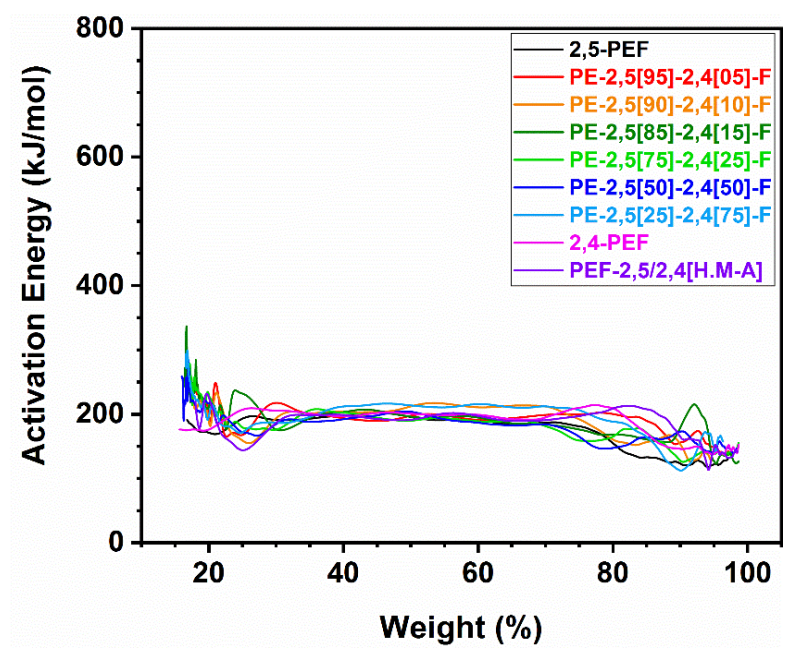

Figure S41: Activation energy for thermal degradation under gaseous nitrogen as a function of the degree of conversion (mass loss) for the polyesters in the EG series obtained by MT-TGA.

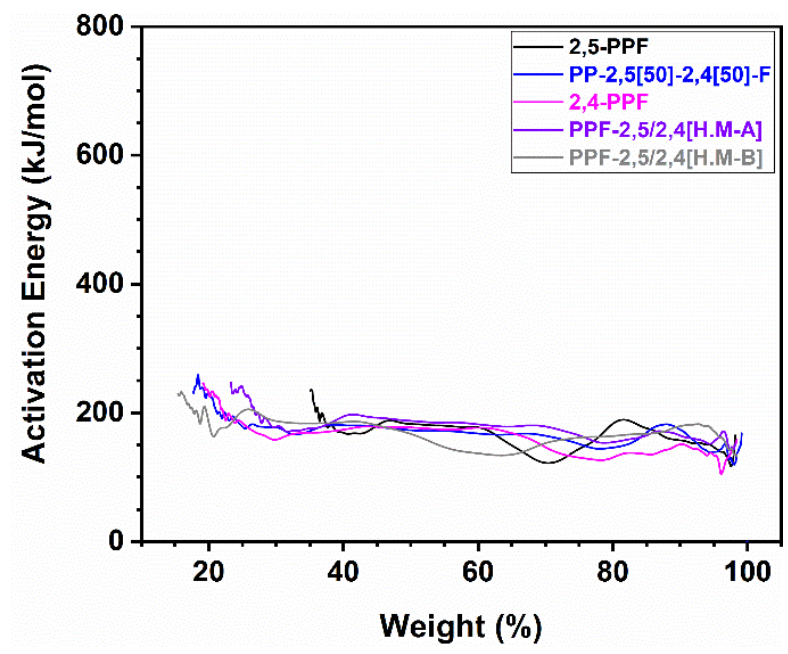

Figure 542: Activation energy for thermal degradation under gaseous nitrogen as a function of the degree of conversion (mass loss) for the polyesters in the PDO series obtained by MT-TGA.

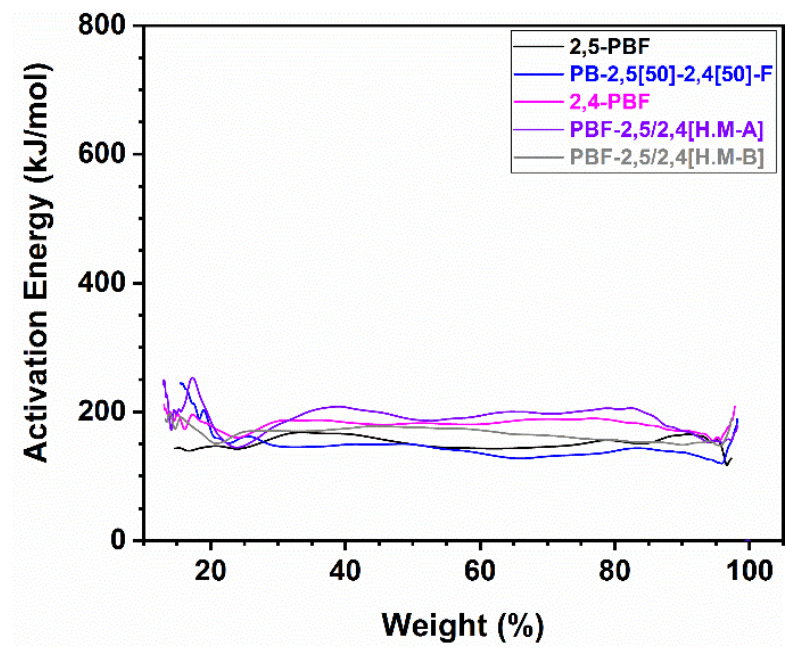

Figure 543: Activation energy for thermal degradation under gaseous nitrogen as a function of the degree of conversion (mass loss) for the polyesters in the BDO series obtained by MT-TGA. 


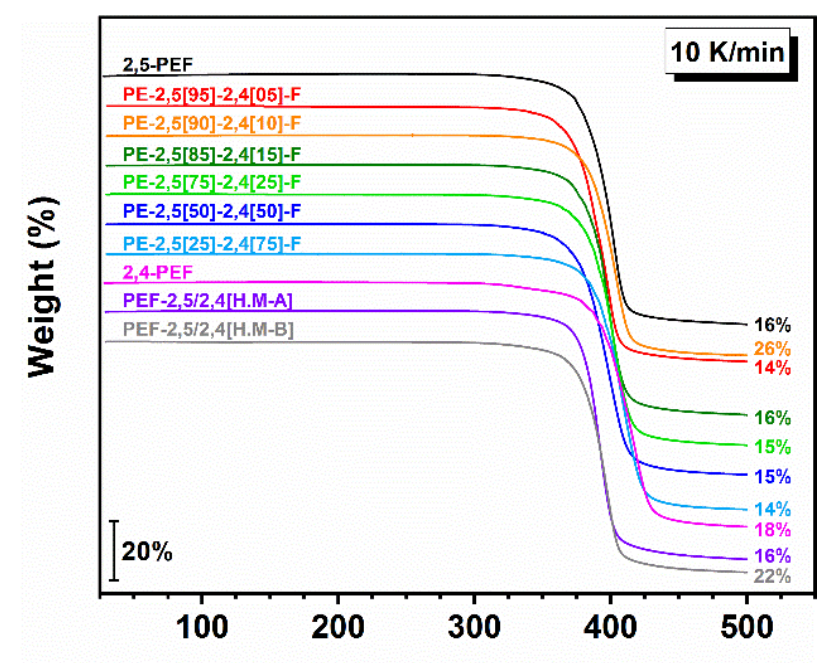

(a)

\section{Temperature $\left({ }^{\circ} \mathrm{C}\right)$}

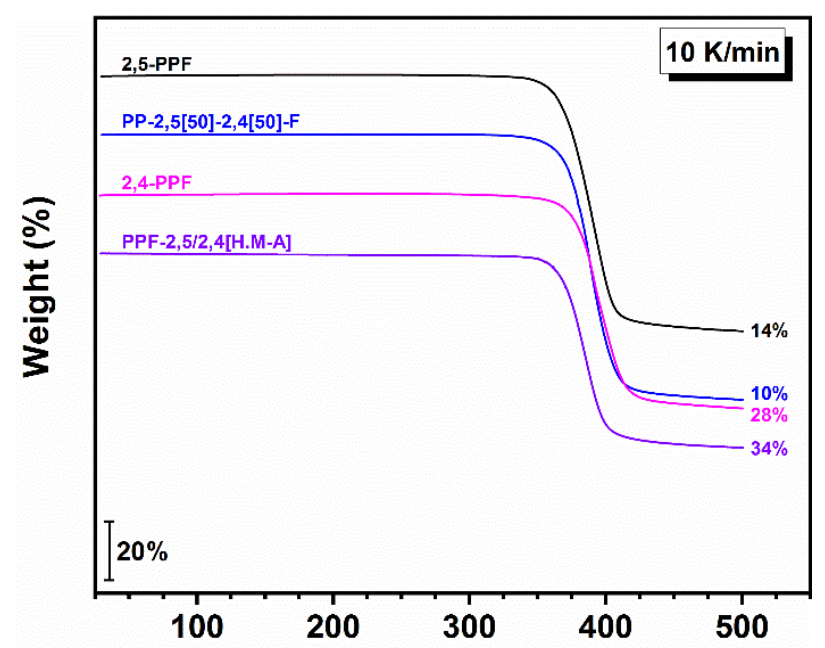

(b)

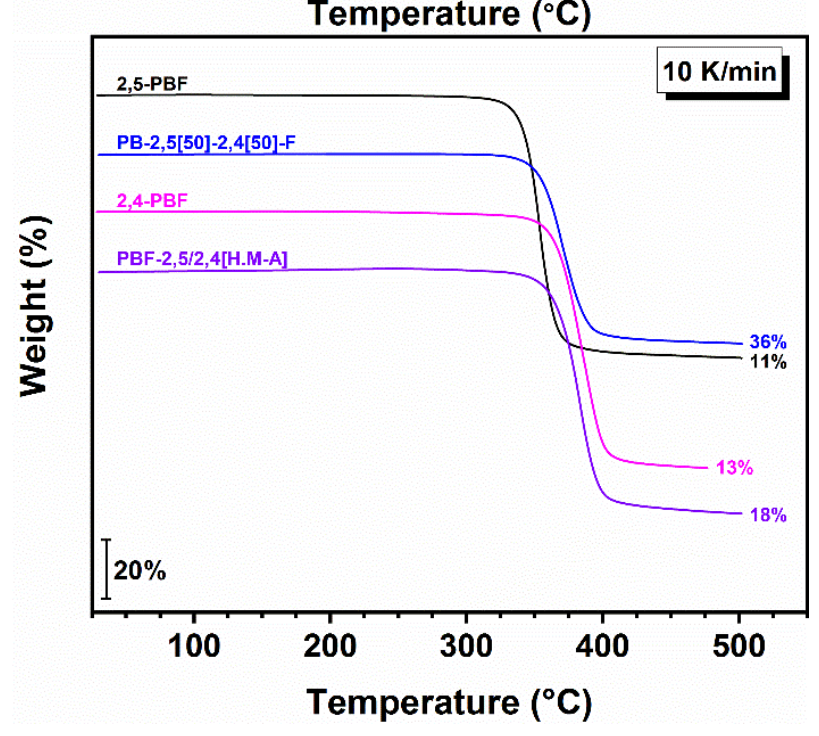

Figure S44: TGA traces for the samples in (a) the EG, (b) the PDO, and (c) the BDO series recorded from 30 to $500{ }^{\circ} \mathrm{C}$ at $10^{\circ} \mathrm{C} \mathrm{min}^{-1}$ under a $\mathrm{N}_{2}$ atmosphere. 


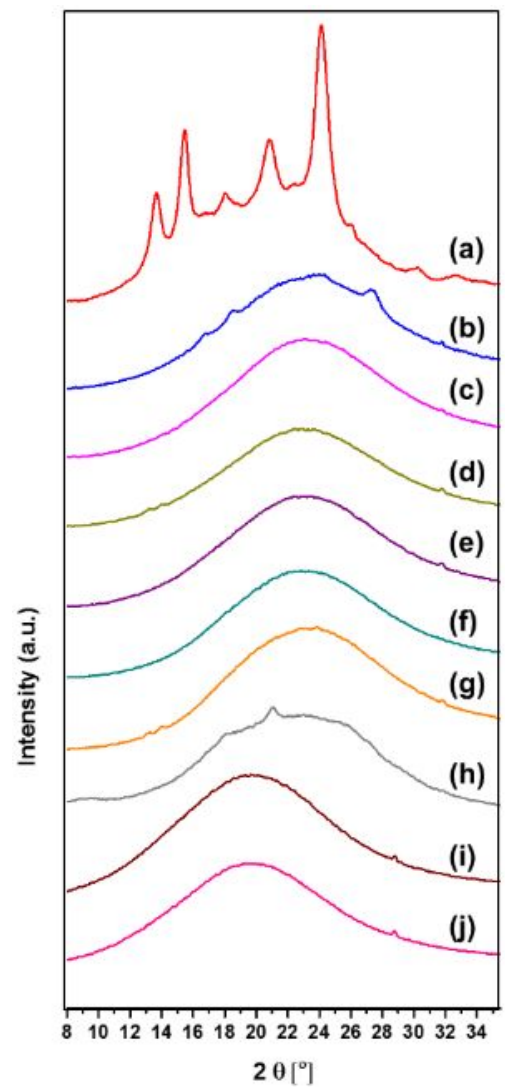

Figure S45: WAXD diffractograms of (a) 2,5-PEF, (b) PE-2,5[95]-2,4[05]-F, (c) PE-2,5[90]-2,4[10]-F, (d) PE-2,5[85]-2,4[15]-F, (e) PE-2,5[75]-2,4[25]-F, (f) PE-2,5[50]-2,4[50]-F, (g) PE-2,5[25]-2,4[75]-F, (h) 2,4-PEF, (i) PEF-2,5/2,4[H.M-A] and (j) PEF-2,5/2,4[H.M-B].

Table S1: Percentage of DEG content in the EG series calculated using ${ }^{1} \mathrm{H}$ NMR spectroscopy.

\begin{tabular}{|l|l|l|}
\hline Entry & Code & $\begin{array}{l}\text { DEG content } \\
(\%)\end{array}$ \\
\hline 1 & $2,5-\mathrm{PEF}$ & 2.4 \\
\hline 2 & PE-2,5[95]-2,4[05]-F & 4.6 \\
\hline 3 & PE-2,5[90]-2,4[10]-F & 3.7 \\
\hline 4 & PE-2,5[85]-2,4[15]-F & 3.5 \\
\hline 5 & PE-2,5[75]-2,4[25]-F & 3.9 \\
\hline 6 & PE-2,5[50]-2,4[50]-F & 6 \\
\hline 7 & PE-2,5[25]-2,4[75]-F & 2.1 \\
\hline 8 & $2,4-P E F$ & 2.3 \\
\hline 9 & PEF-2,5/2,4[H.M-A] & 4.8 \\
\hline 10 & PEF-2,5/2,4[H.M-B] & 6 \\
\hline
\end{tabular}

\section{Modulated-Temperature Thermogravimetric Analysis (MT-TGA):}

Reaction kinetics can be expressed by the rate equation, which gives the relationship between the rate of reaction, time, and the amount of material that progressively undergoes the reaction. The rate of reaction as a function of temperature can be described by the Arrhenius equation. The rate equation and the Arrhenius equation are frequently combined into a single equation of the following form (Eq. 1) $)^{1-2}$ 


$$
\frac{d \alpha}{d t}=Z[f(\alpha)] e^{-E_{\alpha} / R T}
$$

Where $\mathrm{a}$ is the fraction of sample that has already reacted, $\mathrm{da} / \mathrm{dt}$ is the rate of reaction, $\mathrm{Z}$ is a preexponential factor, $f(a)$ is the kinetic expression, $E_{a}$ is the activation energy, $R$ is the universal gas constant, and T is the temperature. MT-TGA is based on a method first proposed by Flynn in 1969.3, which has recently been implemented and patented by TA Instruments. In MT-TGA experiments, a sinusoidal temperature modulation is superimposed on the underlying linear-heating-rate profile used in conventional TGA, which results in an oscillatory response in the rate of weight loss. The kinetic parameters are then obtained by a deconvolution of the oscillatory response via real-time discrete Fourier transform. The activation energy of thermal degradation can be determined at any step of decomposition reaction from Eq. 1:

$$
E_{a}=\frac{R\left(T^{2}-A^{2}\right) L}{2 A}
$$

Where $R$ is the universal gas constant, $T$ is the average temperature, $A$ is the temperature amplitude, and $L$ is the natural logarithmic ratio between the maximum and minimum rates of degradation, as determined from the amplitude of the weight loss signal by the discrete Fourier transform ${ }^{2}$. The calculation of $E_{a}$ can be done without assuming any kinetic model (approach called "model free"). However, a kinetic model must be assumed to calculate log Z.

Assuming a first-order kinetics, $\log Z$ can be obtained from the value of $E_{a}$ via the following equation. ${ }^{1-2}$ :

$$
\log Z=\log \left[\frac{d \alpha}{1-\alpha}\right]+\frac{E_{a}}{2.303 R T}
$$

Where $\mathrm{a}$ is the lost mass fraction, $\mathrm{R}$ is the universal gas constant, and $\mathrm{T}$ is the temperature.

\section{Metrics assessment for the Henkel reaction:}

Atom economy (or efficiency) (AE):

AE is calculated using the molar mass of the desired product obtained against the sum of molar mass values of all the reactants according to the following equation:

$$
\mathrm{AE}=\frac{\text { mol.wt. of desired product }}{\text { sum of mol. wt. of all reactants }} \times 100 \%
$$

The AE for the Henkel reaction is calculated below:

2

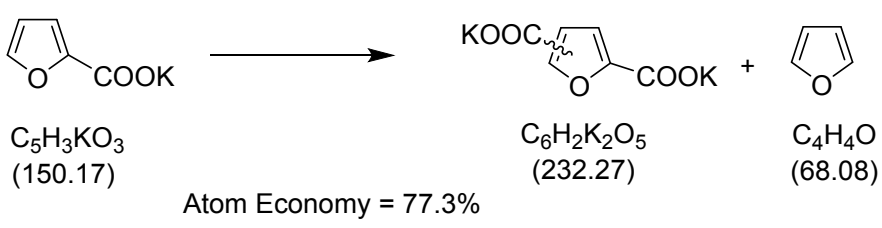

The AE calculated for the Henkel reaction is $77 \%$. It should be pointed out that in this reaction the furan is not lost, but formed as a by-product which is valuable too. Industrially, furan is produced either by catalytic decarbonylation of furfural (which in turn can be derived from biomass as feedstock), or by the 
oxidation of 1,3-butadiene (obtained from fossil resources). Furan is widely used in many application areas, e.g. as a precursor for producing tetrahydrofuran (THF), a chief solvent for many organic reactions, as a substrate in the Diels-Alder reaction for the production of biobased aromatics, and as a precursor for the production of various speciality chemicals. Besides $A E$, the Henkel reaction offers other advantages such as : it is a solvent-less one-pot reaction which allows to obtain 2,5- and 2,4-furandicarboxylic acid isomers at the same time, along with furan as a valuable by-product.

Process Mass intensity (PMI):

PMI is calculated as the ratio of the total mass of materials used to the mass of the isolated product.

PMI $=\frac{\text { mass of raw materials input }}{\text { mass of desired output }}$

It is relatively easy to calculate PMI for the Henkel-type reaction, since the reaction does not require any solvents or reagents. Selecting the best results obtained, the PMI for the Henkel reaction is calculated to a value of 1.6 , which falls within the range of oil refining and bulk chemical industrial processes with the annual production of 104-108 tonnage. ${ }^{4}$.

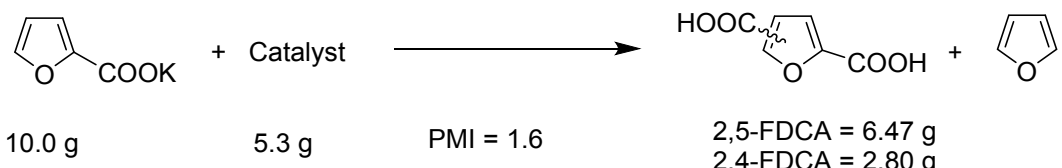

References:

1. Blaine, R. L.; Hahn, B. K., Journal of Thermal Analysis and Calorimetry 1998, 54 (2), 695-704.

2. Blaine, R., American Laboratory 1998, 30 (1), 21-23.

3. Flynn, J. H. In Thermal Analysis, Schwenker, R. F., Garn, P. D., Eds. Academic Press: 1969; pp 1111-

1126.

4. Roschangar, F.; Sheldon, R. A.; Senanayake, C. H., Green Chemistry 2015, 17 (2), $752-768$. 